\title{
MAGE-D1 Regulates Expression of Depression-Like Behavior through Serotonin Transporter Ubiquitylation
}

\author{
Akihiro Mouri, ${ }^{1,6 *}$ Aya Sasaki, ${ }^{2,3 *}$ Ken Watanabe, ${ }^{2}$ Chiharu Sogawa, ${ }^{4}$ Shigeo Kitayama, ${ }^{4}$ Takayoshi Mamiya, ${ }^{1}$ \\ Yoshiaki Miyamoto, ${ }^{5}$ Kiyofumi Yamada, ${ }^{6}$ Yukihiro Noda, ${ }^{7,8,9}$ and Toshitaka Nabeshima ${ }^{1,8,9}$ \\ ${ }^{1}$ Department of Chemical Pharmacology, Meijo University Graduate School of Pharmaceutical Sciences, Nagoya 468-8503, Japan, ${ }^{2}$ Department of Bone and Joint \\ Disease, National Center for Geriatrics and Gerontology, Obu 474-8511, Japan, ${ }^{3}$ Department of Pathology, School of Medicine, Keio University, Tokyo 160-8582, \\ Japan, ${ }^{4}$ Department of Dental Pharmacology, Okayama University Graduate School of Medicine, Dentistry and Pharmaceutical Sciences, Okayama 700-8558, Japan, \\ ${ }^{5}$ Department of Pharmaceutical Therapy and Neuropharmacology, Faculty of Pharmaceutical Sciences, Graduate School of Medicine and Pharmaceutical Sciences, \\ University of Toyama, Toyama 930-0194, Japan, ${ }^{6}$ Department of Neuropsychopharmacology and Hospital Pharmacy, Nagoya University Graduate School of \\ Medicine, Nagoya 466-8560, Japan, ${ }^{7}$ Division of Clinical Sciences and Neuropsychopharmacology, Meijo University Graduate School of Pharmaceutical Sciences, \\ Nagoya 468-8503, Japan, ${ }^{8}$ The Academic Frontier Project for Private Universities, Comparative Cognitive Science Institutes, Meijo University, Nagoya 468-0069, \\ Japan, and ${ }^{9}$ Japanese Drug Organization of Appropriate Use and Research, Nagoya 468-0069, Japan
}

The ubiquitin-proteasome system (UPS) controls the stability of most cellular proteins. The polymorphism of UPS-related genes is associated with major depression disorder, but less is known about the molecule that plays a role in depression by modulating the UPS. Melanoma antigen gene-D1 (MAGE-D1) interacts with RING E3 ubiquitin ligase and is implicated in protein degradation. MAGE-D1 may thus play an important role in the CNS via ubiquitylation. Here, we clarified a novel role of MAGE-D1 in emotional functions, namely its modulation of ubiquitylation to the serotonin transporter (SERT). The MAGE-D1 knock-out and knockdown by small interfering RNA (siRNA) in the prefrontal cortex showed depression-like behavior, such as a decrease in exploratory behavior in both the home cage and novel apparatus, a decrease in social interaction, increased immobility time during forced swimming and tail suspension, and a decrease in sucrose preference without any anxiety, or cognitive or motor dysfunction. Acute and chronic ( $28 \mathrm{~d})$ administration of sertraline (10 $\mathrm{mg} / \mathrm{kg})$ and imipramine $(20 \mathrm{mg} / \mathrm{kg})$ reversed all or part of depression-like behavior in knock-out mice. In these mice, the serotonergic function in the prefrontal cortex and hippocampus was hypoactive, accompanied by hyperexpression of SERT attributable to a decrease in ubiquitylation. Furthermore, MAGE-D1 binds to SERT via the necdin homology domain. MAGE-D1 overexpression in cells resulted in a decrease in serotonin uptake activity and the protein level of SERT but an increase in ubiquitylated SERT. Together, the present findings suggest a novel role for MAGE-D1 in depressive behaviors: modulating SERT ubiquitylation.

\section{Introduction}

Major depression disorder is a serious illness characterized by fatigue, diminished interest or pleasure in everyday activities, and

Received Dec. 25, 2011; revised Feb. 2, 2012; accepted Feb. 6, 2012.

Author contributions: A.M. and T.N. designed research; A.M., C.S., and Y.N. performed research; A.S., K.W., C.S., and S.K. contributed unpublished reagents/analytic tools; A.M., A.S., T.M., Y.M., K.Y., and Y.N. analyzed data; A.M., K.W., S.K., T.M., Y.N., and T.N. wrote the paper.

*A.M. and A.S. contributed equally to this work.

This study was supported by Grants-in-Aid for Scientific Research (A) Grant 22248033, Scientific Research (B) Grants 20390073 and 21390045, Young Scientists (B) Grants 22790233 and 23791325, and Exploratory Research Grants 19659017 and 22659213, and the "Academic Frontier" Project for Private Universities Grant 2007-2011 by the Ministry of Education, Culture, Sports, Science, and Technology of Japan; by the Regional Joint Research Program, supported from grants to Private Universities to Cover Current Expenses from the Ministry of Education, Culture, Sports, Science, and Technology; by the Project for Researching the Regulation of Pharmaceuticals and Medical Devices (Ministry of Health and Labour and Welfare); by Grants for Research into the Risks of Chemical Substances and Health and Labour Science Research Grants provided by the Ministry of Health, Labour, and Welfare; by a joint research project under the auspices of the Japan-Korea Basic Scientific Cooperation Program (Japan Society for the Promotion of Science); and by the Brain Research Center's 21stCentury Frontier Research Program, supported by the Ministry of Science and Technology, Republic of Korea.

The authors declare no competing financial interests.

Correspondence should be addressed to Toshitaka Nabeshima, 150 Yagotoyama, Tenpaku-ku, Nagoya 4688503, Japan. E-mail: tnabeshi@ meijo-u.ac.jp.

DOI:10.1523/JNEUROSCI.6458-11.2012

Copyright $\odot 2012$ the authors $\quad 0270-6474 / 12 / 324562-19 \$ 15.00 / 0$ despair (Cryan and Holmes, 2005), with a possibility of occurrence during a person's lifetime as high as 20\% (Kessler et al., 2005). Twin studies that compare behaviors among monozygotic and dizygotics twins suggest that genetic influences are responsible for $\sim 30$ to $40 \%$ of adult and adolescent major depression disorder (Sullivan et al., 2000; Rice et al., 2002). The ubiquitinproteasome system (UPS) controls the stability of most cellular proteins. Genetic association studies have revealed that the polymorphisms of UPS-related genes are associated with major depression disorder (Fukuo et al., 2011) and antidepressant response (Garriock et al., 2010). Studies have also shown that the expression of the UPS-related gene is disturbed in patients with mood disorders, including depression (Ryan et al., 2006; Gormanns et al., 2011). Although UPS has been found to play a critical role in synaptic trafficking (Wheeler et al., 2002; Yao et al., 2007) and affect behavioral despair (Tomida et al., 2009), little is known about the molecule that plays a role in creating a depressive state by modulating the UPS.

Melanoma antigen genes (MAGE) are localized in clusters in the $\mathrm{X}$ chromosome and can be broadly categorized into two types: cancer testis antigen type I and ubiquitous type II (Barker 
and Salehi, 2002; Sasaki et al., 2005). MAGE-D1 (also known as Dlxin-1or NRAGE) is found in bone marrow stromal cells (Põld et al., 1999) and categorized as a member of the type II MAGE family, which is characterized by the presence of a unique region of $\sim 200$ amino acids known as the MAGE homology domain (Barker and Salehi, 2002; Sasaki et al., 2005). The roles of MAGE-D1 have been explored by the identification and analysis of a number of associated proteins in vitro. MAGE-D1 plays a role in apoptosis by interaction with the p75 receptor (Salehi et al., 2000), UNC5H1(Williams et al., 2003), and ITA and XIAP (Jordan et al., 2001) and transcription by interaction with the Dlx5 (Masuda et al., 2001) and Ror2 (Matsuda et al., 2003). Notably, it has been suggested that MAGE-D1 plays the role of an adaptor molecule in ubiquitin-dependent degradation pathways. Praja-1, one of the RING E3 ubiquitin ligases, has been identified as an MAGE-D1 binding protein and inhibits Dlx5-dependent transcriptional activity (Sasaki et al., 2002). It has also been reported that not only MAGE-D1 but also other type I and II MAGE family members bind to and activate RING E3 ubiquitin ligases (Doyle et al., 2010). Another finding has been that the expression of MAGE-D1 is detected in most adult tissues, predominantly in the brain (Masuda et al., 2001). Thus, MAGE-D1 may play an important role in the CNS through ubiquitylation. However, the physiological roles of MAGE-D1 in emotional and cognitive functions are still unclear.

Here, we clarified a novel role of MAGE-D1 in emotional function related to modulation of ubiquitylation to the serotonin transporter (SERT). Our finding revealed the following: (1) MAGE-D1 deficiency induces antidepressant-sensitive depression-like behavior via hyposerotonergic function associated with hyperexpression of SERT; and (2) MAGE-D1 binds to SERT and regulates its activity and expression by ubiquitylation.

\section{Materials and Methods}

\section{Mice}

Male and female C57BL/6J mice ( 7 weeks old; male, $n=142$; female, $n=$ 36, including unfamiliar social partners) were obtained from Japan SLC. MAGE-D1 knock-out (KO) mice (male: wild-type, $n=124 ; \mathrm{KO}, n=$ 121; female: wild-type, $n=12$; heterozygous, $n=12$; $\mathrm{KO}, n=12$ ) were as described below. The mice were housed in plastic cages and kept in a regulated environment $\left(24 \pm 1^{\circ} \mathrm{C}, 50 \pm 5 \%\right.$ humidity), with a $12 \mathrm{~h}$ light/dark cycle (lights on at 8:00 A.M.). Food and tap water were available ad libitum. All experiments were performed in accordance with the Meijo University Guidelines for Animal Experiments. The procedures involving mice and their care were conducted in conformity with international guidelines, specifically, the Principles of Laboratory Animal Care (National Institutes of Health Publication 85-23, revised 1985).

\section{Generation of MAGE-D1 KO mice}

Genomic DNA clones of the Maged1 locus were isolated from a mouse $129 /$ Svj genomic library (Stratagene) using full-length mouse Dlxin-1 cDNA as a probe (Masuda et al., 2001). The genomic region of the coding exons was replated with a neo cassette (Fig. $1 \mathrm{~A}$ ). The gene encoding thymidine kinase was inserted into the $3^{\prime}$ end of the long arm for negative selection. The targeting vector was linearized and electroporated into E14 embryonic stem cells, and clones were selected in G418 and Ganciclovir. Targeting events were screened by PCR and confirmed by Southern blotting analysis. Chimeric mice generated by the ES cell injection were mated with C57BL/6J mice to obtain F1 Maged1 heterozygous mice. The germ-line-transmitted F1 mice were backcrossed $\geq 10$ times (N10) with C57BL/6J; the analyses in this study were conducted using the N10 mice. Because the Maged1 gene is located on the $\mathrm{X}$ chromosome, genotype distribution was as follows: wild-type $(+/ y)$ and $\mathrm{KO}(-/ y)$ in males and wild-type $(+/+)$, heterozygous $(+/-)$, and $\mathrm{KO}$ $(-/-)$ in females. Thus, the Maged $1^{-l y}$ males and Maged $1^{-/-}$females were designated as $\mathrm{KO}$ mice in this study. The genotypes of mice were determined by PCR (Fig. $1 A, C$ ). The wild-type allele ( $561 \mathrm{bp}$ ) was detected using as a forward primer (DXN EXF2, $5^{\prime}$-CACCACATTCCGCACCAG-3') and as a reverse primer (DXN 580R, 5'-ACCTTTAGGGGTGCCATTCTG-3'). To detect the mutant allele (1419 bp), a neomycin-specific reverse primer (G7, $5^{\prime}$-GGGTGGGGTGGGATTAGATAAATG-3') was used in combination with the wild-type forward primer (P3, 5'-ATTCCTGTTTTGGATAGT AGTGAG-3').

\section{siRNA infusion}

For the infusion of siRNA, C57BL/6J mice were anesthetized with sodium pentobarbital ( $40 \mathrm{mg} / \mathrm{kg}$, i.p.) and bilaterally implanted with a guide cannula ( $6 \mathrm{~mm}, 0.4 \mathrm{~mm}$ inner diameter, $0.5 \mathrm{~mm}$ outer diameter; Eicom) in the prefrontal cortex (coordinates: $+1.5 \mathrm{~mm}$ anteroposterior, $\pm 0.5 \mathrm{~mm}$ mediolateral from the bregma, $-2.0 \mathrm{~mm}$ dorsoventral from the skull). To seal the top of the guide cannula and prevent tissue entry into the cannula, a dummy cannula $(0.3 \mathrm{~mm}$ in diameter; Eicom) was left in place throughout the experiment. One day after recovery from surgery, mice were injected with siRNA. MAGE-D1 (5'-AACCUCAGUAUCAGCCUUC-3') and negative control (Takezawa et al., 2009) siRNA (Nippon EGT) were diluted to 0.75 $\mathrm{mg} / \mathrm{ml}$ in Invivofectamine 2.0 reagent (Invitrogen). After $30 \mathrm{~min}$ of incubation at $50^{\circ} \mathrm{C}, 1 \mu \mathrm{l}$ was injected into each prefrontal cortex through an infusion cannula ( $6.2 \mathrm{~mm}, 0.3 \mathrm{~mm}$ in diameter; Eicom) that was connected to a microsyringe by a polyethylene tube. The entire infusion procedure took 2 min, and mice were handled gently to minimize stress. After three infusions of siRNA ( $1.5 \mu \mathrm{g}$ of siRNA per prefrontal cortex per day), mice were subjected to a sequence of behavioral tests (locomotor activity test, social interaction test, sucrose preference test, forced swimming test, and tail suspension test). During these behavioral tests, siRNA infusion was continued. Each behavioral test was performed $24 \mathrm{~h}$ after the siRNA infusion.

\section{Drug administration}

Sertraline, obtained from Pfizer, was suspended in saline containing $0.3 \%(\mathrm{w} / \mathrm{v})$ carboxymethyl cellulose sodium. Imipraimine, purchased from Sigma, was dissolved in $0.9 \% \mathrm{NaCl}$ solution. All compounds were acutely or chronically ( $28 \mathrm{~d}$ ) injected intraperitoneally. The injection volumes were $10 \mathrm{ml} / \mathrm{kg}$ for mice. Behavioral tests were performed $30 \mathrm{~min}$ after acute treatment or $24 \mathrm{~h}$ after chronic treatment.

\section{Behavioral analysis}

All behavioral analysis was performed between 10:00 A.M. and 6:00 P.M. except in the case of a circadian rhythm activity test. To investigate the behavior of MAGE-D1 KO mice, the mice were divided into three groups. The behavioral tests for group 1 were a circadian rhythm activity test, spontaneous locomotor activity test, open-field test, elevated plus maze test, social interaction test, and forced swimming test; the tests were performed in the sequence indicated here. The behavioral tests for group 2 were a Y-maze test, novel-object recognition test, water finding test, cued and contextual fear conditioning tests, and rotarod test; they were also performed in the sequence indicated here. The behavioral test for group 3 was a sucrose preference test. To reduce the influence of previous experiments, the sequences of behavioral tests were in order of degree of stress, from low (e.g., the circadian rhythm activity test) to high (e.g., the forced swimming test). Behavioral experiments were performed in a sound-attenuated and air-regulated experimental room, to which mice were habituated for $\geq 1 \mathrm{~h}$.

Circadian rhythm activity test. The circadian rhythm activity test was performed according to the method outlined in previous reports (Hofstetter et al., 2005; Kasahara et al., 2006) with a minor modification. Locomotor activity was measured using an infrared detector (Brain Science Idea) in each transparent cage $(32 \times 22 \times 15 \mathrm{~cm}$ high). Mice were placed in the cages individually, and locomotor activity was measured every $1 \mathrm{~h}$ for $52 \mathrm{~h}$.

Spontaneous locomotor activity test. The spontaneous locomotor activity test was performed according to the method outlined in previous reports (Miyamoto et al., 2001) with a minor modification. To measure locomotor activity in a novel environment, a mouse was placed in a transparent acrylic cage with a black frosted Plexiglas floor $(45 \times 26 \times 40$ $\mathrm{cm}$ ), and locomotion and rearing were measured every $5 \mathrm{~min}$ for $60 \mathrm{~min}$ using digital counters with infrared sensors (Scanet SV-10; Melquest).

Open-field test. The open-field test was performed according to the method outlined in previous reports (Walsh and Cummins, 1976; 

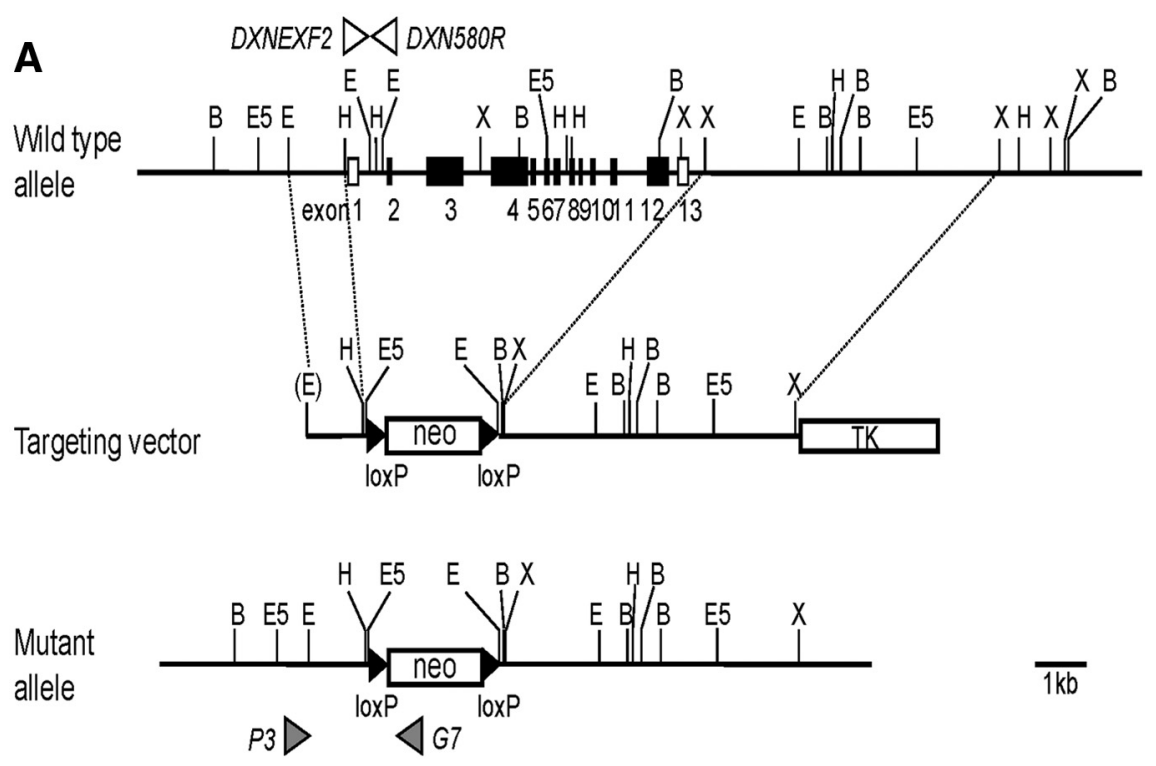

$\overline{1 \mathrm{~kb}}$

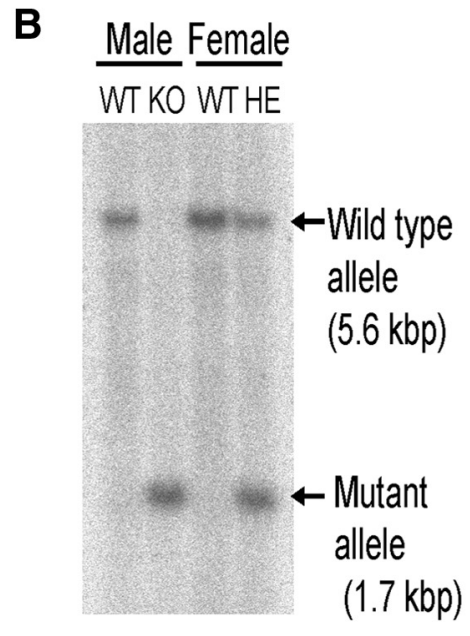

C

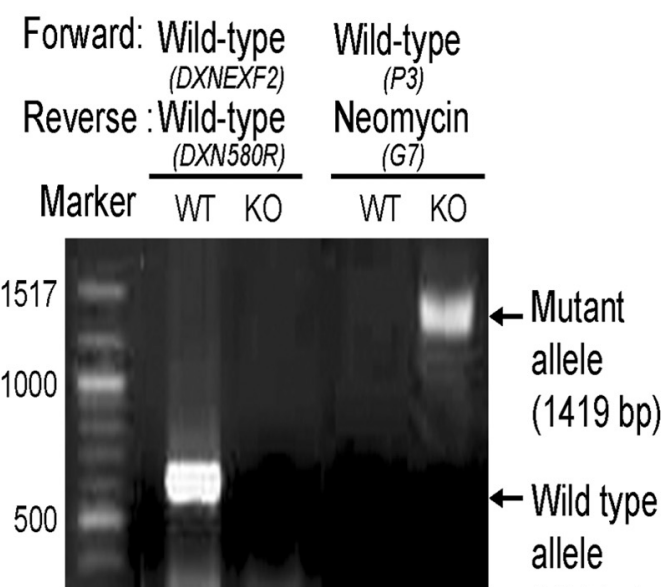

(561 bp)

D

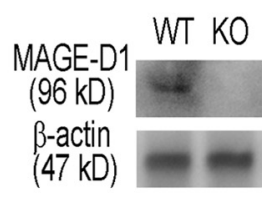

$E$

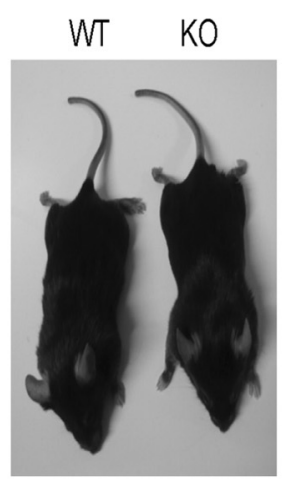

Figure 1. Generation and general characteristics of the MAGE-D1 KO mice. A, Strategy for disrupting the Maged1 gene. The schematic map of Maged 1 shows that whole exons 1 through 12 were replaced by the PGK-Neo cassette. $\boldsymbol{B}$, Southern blotting of tail DNA from wild-type and mutant alleles, indicating expected band sizes of 5.6 and $1.7 \mathrm{~kb}$, respectively. C, Genotyping was performed by $P C R$ and gel electrophoresis. The wild-type allele $(561 \mathrm{bp})$ and mutant allele ( $1419 \mathrm{bp})$ were identified by PCR using wild-type forward and reverse primers and the wild-type forward primer and neomycin-specific reverse primer, respectively. $\boldsymbol{D}$, Protein expression of MAGE-D1 in the MAGE-D1 KO mice: protein extracts from the whole brains of wild-type and MAGE-D1 KO mice were examined by Western blotting. $E$, Representative examples of wild-type and MAGE-D1 KO mice at 3 months old. WT, Wild-type mice; HE, MAGE-D1 heterozygous mice.

Yamada et al., 2000) with minor modifications. The open field consisted of a circular arena with a total diameter of $60 \mathrm{~cm}$ and a height of $30 \mathrm{~cm}$. Inner and outer circles $(12$ and $36 \mathrm{~cm}$ in diameter) divided the arena into three areas (center, middle, and outer zones). The middle and outer zones were radially divided into 8 and 16 sections, respectively. A light $(50 \mathrm{~W})$ was positioned $100 \mathrm{~cm}$ above the center of the floor. Each mouse was placed in a section of the outer zone and then allowed to freely explore its environment. The time until the mouse moved to another section was counted as its starting latency. The amount of time spent in each zone and total distance moved were measured for $5 \mathrm{~min}$ using images captured on video (Etho Vision System; Brain Science Idea). The number of rearing, grooming, defecation, and urination events was recorded.

Elevated plus-maze test. The elevated plusmaze test was performed according to the method outlined in previous reports (Lister, 1987; Miyamoto et al., 2002) with minor modifications. The elevated plus-maze consisted of two open $(25 \times 8 \times 0.5 \mathrm{~cm})$ and two closed $(25 \times 8 \times 20 \mathrm{~cm})$ arms extending from a common central platform $(8 \times 8 \mathrm{~cm})$ to form a plus shape. The entire apparatus was elevated to a height of $50 \mathrm{~cm}$ above the floor level. The test was started by placing a mouse on the central platform of the maze facing an open arm. The frequency of entry into the open and closed arms and total distance moved were measured for 10 min using images captured on video (Etho Vision System; Brain Science Idea). The data were then used to calculate the percentage of open-arm entries [i.e., (open arms entries/ open- and closed-arms entries) $\times 100]$.

Social interaction test. The social interaction test was performed according to the method outlined in previous reports (Qiao et al., 2001; Lu et al., 2009). The apparatus used for the social interaction test consisted of a square open arena $(25 \times 25 \times 30 \mathrm{~cm})$ with no top, made of gray nonreflecting acrylic, illuminated with lamps that could not be seen by the mice directly. The light was diffused to minimize shadows in the arena. Each mouse was placed alone in the test box for $10 \mathrm{~min}$ on 2 consecutive days before the social interaction test (habituation). On the test day, each mouse was randomly assigned to a same-gender 7-weekold C57BL/6J mouse used as an unfamiliar partner. The mouse and the unfamiliar partner were placed in the box for $10 \mathrm{~min}$. The duration of social interaction (sniffing, grooming, following, mounting, and crawling but not aggressive behavior) was recorded. Passive contact (sitting or lying with bodies in contact) was not included in the social interaction time.

Forced swimming test. The forced swimming test was performed according to the method outlined in previous reports (Porsolt et al., 1977b; Murai et al., 2007) with a minor modification. Each mouse was placed in a transparent glass cylinder $(20 \mathrm{~cm}$ high, $15 \mathrm{~cm}$ in diameter), which contained water at $22^{\circ} \mathrm{C}$ to a depth of $13 \mathrm{~cm}$ and was forced to swim for 10 $\mathrm{min}$. The duration of swimming was measured 
using a Scanet MV-10 AQ apparatus (Melquest). The immobility time was calculated as follows: Immobility time $(\mathrm{s})=$ total time - swimming time.

Tail suspension test. The tail suspension test was performed according to the method outlined in previous reports (Thierry et al., 1984; Tomida et al., 2009) with a minor modification. The mice were suspended by their tails using a string attached to the tails with adhesive tape $(\sim 1 \mathrm{~cm}$ from the tip of the tail), and the string was hooked on a horizontal rod. The distance between the tip of the nose of each mouse and the floor was $\sim 20 \mathrm{~cm}$. The mice were suspended for $10 \mathrm{~min}$, and the duration of immobility was measured using images captured on video (Etho Vision System; Brain Science Idea).

Sucrose preference test. The sucrose preference test was conducted according to the method outlined in previous reports (Pothion et al., 2004; Sclafani, 2006) with a minor modification. Mice were individually housed and first trained to consume water from two bottles for $24 \mathrm{~h}$. The next day, a bottle of water was replaced with a bottle filled with $1 \%$ sucrose solution. [The $1 \%$ concentration was chosen on the basis of a reported preference of $\mathrm{C} 57 \mathrm{BL} / 6 \mathrm{~J}$ mice for a sucrose solution at this concentration (Sclafani, 2006)]. The amount of the sucrose solution or water consumed was determined by weighing the bottles every $24 \mathrm{~h}$ for $6 \mathrm{~d}$. To prevent potential location preference for drinking, the position of the bottles was changed every $48 \mathrm{~h}$. The preference for the sucrose solution was calculated as the percentage of sucrose solution ingested relative to the total amount of liquid consumed.

$Y$-maze test. The Y-maze test was performed in accordance with the method outlined in previous reports (Sarter et al., 1988; Mouri et al., 2007a). The maze was made of black painted wood; each arm was $40 \mathrm{~cm}$ long, $12 \mathrm{~cm}$ high, $3 \mathrm{~cm}$ wide at the bottom, and $10 \mathrm{~cm}$ wide at the top. The arms converged at an equilateral triangular that was $4 \mathrm{~cm}$ at its longest axis. Each mouse was placed at the center of the apparatus and allowed to move freely through the maze during an $8 \mathrm{~min}$ session. Arm entries were recorded by video camera. Alternation was defined as successive entry into the three different arms, counting overlapping triplet sets. Alternation behavior (percentage) was calculated as the ratio of actual alternations to possible alternations (defined as the number of arm entries -2 ), multiplied by 100 .

Water finding test. The water finding test was performed according to the method outlined in previous reports (Ettenberg et al., 1983; Mouri et al., 2007b). The apparatus consisted of an open field $(30 \times 50 \times 15 \mathrm{~cm}$ high) with an alcove $(10 \times 10 \times 10 \mathrm{~cm}$ high $)$ in the middle of one of the long walls of the enclosure. The floor of the open field was divided into 15 identical squares for measuring locomotor activity. A drinking tube, identical to that used in the home cage, was inserted into the center of the alcove ceiling with its tip $6.5 \mathrm{~cm}$ (in the training trial) or $7.5 \mathrm{~cm}$ (in the test trial) above the floor to decrease the probability of its being found by chance in the test trial. Briefly, the task consisted of two trials: a training trial (the first day) and a test trial (the second day). In the training trial, mice were placed individually into one corner of the open field of the apparatus and were allowed $3 \mathrm{~min}$ to explore the environment. The time until the mouse moved out of the corner was measured as the starting latency. During this time, ambulation was measured by counting the number of times the mouse crossed from one square to another in the open field. The frequency of touching, sniffing, or licking of the water tube in the alcove (number of approaches) was also recorded. Mice that did not find the drinking tube during the 3 min exploratory period were omitted from the test trial. The mice were immediately returned to their home cages after the training trial and deprived of water for $24 \mathrm{~h}$ until the test trial. Nontrained mice were prepared for comparison with the trained mice in terms of their ability to find the water source in the same environment. In the test trial, mice were again individually placed on the test apparatus. The time between entering the alcove and drinking the water (finding latency) was measured. If the mice could not find the drinking tube within $5 \mathrm{~min}$, the test trial was terminated.

Novel-object recognition test. The novel-object recognition test was performed in accordance with the method outlined in previous reports (Dodart et al., 1997; Mouri et al., 2007a). The test procedure consisted of three sessions: habituation, training, and retention. Each mouse was individually habituated to a Plexiglas box $(30 \times 30 \times 35$ high $\mathrm{cm})$ by being given 10 min exploration time in the box without any objects present for $3 \mathrm{~d}$ (habituation session). During the training session, two objects were placed in a back corner of the box. The objects were a golf ball, wooden cylinders, and square pyramids, which were different in shape and color but similar in size. A mouse was then placed midway toward the front of the box, and the total time it spent exploring the two objects was recorded for $10 \mathrm{~min}$. A mouse was considered to be exploring the object when its head was facing the object or it was touching or sniffing the object. During the retention session, the mouse was placed back into the same box $24 \mathrm{~h}$ after the training session, but one of the familiar objects used during training was replaced with a novel object. The mouse was then allowed to explore freely for $10 \mathrm{~min}$, and the time spent exploring each object was recorded. Throughout the experiments, the objects were used in a counterbalanced manner in terms of their physical complexity and emotional neutrality. A preference index, a ratio of the amount of time spent exploring any one of the two objects (training session) or the novel object (retention session) over the total time spent exploring both objects was used to measure cognitive function.

Cued and contextual fear conditioning tests. The cued and contextual fear conditioning tests were performed in accordance with the method outlined in previous reports (Paylor et al., 1994; Mouri et al., 2010). For measuring basal levels of freezing response (preconditioning phase), mice were individually placed in a neutral cage $(17 \times 27 \times 12.5$ high cm $)$ for $1 \mathrm{~min}$ and then in the conditioning cage $(25 \times 31 \times 11$ high $\mathrm{cm})$ for $2 \mathrm{~min}$. For training (conditioning phase), mice were placed in the conditioning cage, and then a $15 \mathrm{~s}$ tone $(80 \mathrm{~dB})$ was delivered as a conditioned stimulus. During the last $5 \mathrm{~s}$ of the tone stimulus, a foot shock of $0.6 \mathrm{~mA}$ was delivered as an unconditioned stimulus through a shock generator (Brain Science Idea). This procedure was repeated four times at $15 \mathrm{~s}$ intervals.

Cued and contextual tests were performed $1 \mathrm{~d}$ after fear conditioning. For the cued test, the freezing response was measured in the neutral cage for $1 \mathrm{~min}$ in the presence of a continuous-tone stimulus identical to the above-mentioned conditioned stimulus. For the contextual test, mice were placed in the conditioning cage, and the freezing response was measured for $2 \mathrm{~min}$ in the absence of the conditioned stimulus.

Rotarod test. The rotarod test was performed according to the method outlined in previous reports (Plotnikoff et al., 1962; Iida et al., 1999) with minor modifications. The test was performed using an accelerating rotarod (MK-600; Muromachi Kikai). A mouse was placed with its four paws on a $3.0-\mathrm{cm}$-diameter bar, $13.5 \mathrm{~cm}$ above the floor, which was rotating at $6 \mathrm{rpm}$. The time the mouse was able to maintain its balance walking on top of the rod was measured. If the mouse was able to remain on the rod over $60 \mathrm{~s}$, the trial was terminated. The mouse was subjected to five such trials in total.

\section{Cell culture and preparation of stably expressed SERT}

Chinese hamster ovary $(\mathrm{CHO})$ cells were cultured in minimum essential medium- $\alpha$ supplemented with $10 \%$ fetal bovine serum, $100 \mathrm{U} / \mathrm{ml}$ penicillin G, $100 \mu \mathrm{g} / \mathrm{ml}$ streptomycin, and $2.5 \mu \mathrm{g} / \mathrm{ml}$ fungisone. Full-length cDNA encoding rat serotonin transporter (rSERT) was subcloned into the mammalian expression vector pcDNA3, as described previously (Sato et al., 2000). To establish lines of CHO cells stably expressing rSERT, CHO cells at subconfluence were transfected with rSERT/ pcDNA3 using FuGENE6 transfection reagent, in accordance with the directions of the manufacturer. After transfection, the cells were incubated for $48 \mathrm{~h}$ and then placed in culture medium containing G418 600 $\mathrm{mg} / \mathrm{ml}$ for 2 weeks to make it possible to select stably transfected cells. Cells were screened for expression using an $\left[{ }^{3} \mathrm{H}\right]$ serotonin uptake assay, and the clones that displayed the highest serotonin uptake was selected for the experiment and designated a CHO-rSERT cell.

\section{Transfection}

The expression vectors pHA-DXN (full-length mouse MAGE-D1 with HA epitope tagging at the $\mathrm{N}$ terminus), pHA-DXN-NHD (MAGE-D1 fragment containing the whole necdin/MAGE homology domain), pHA-DXN-W (MAGE-D1 fragment containing 18 of 25 WQXPXX repeat), and pHA-DXN-N (MAGE-D1 fragment containing N-terminal MAGE-D1) were constructed as described previously (Sasaki et al., 
2002). CHO-rSERT cells were transiently transfected with these vectors by FuGENE (Roche Diagnostics) as indicated in the instructions of the manufacturer.

\section{Western blotting analysis}

Western blotting was performed as described previously (Mouri et al., 2007b). The mice were killed by decapitation, and the brains were immediately removed. Each frontal cortex was rapidly removed on an ice-cold plate, frozen, and stored at $-80^{\circ} \mathrm{C}$ until used. To prepare tissue extracts, the brain tissue was homogenized by sonication in an ice-cold lysis buffer (20 mм Tris-HCl, pH 7.4, 150 mm NaCl, 50 mm NaF, 2 mм EDTA, 0.1\% SDS, $1 \%$ sodium deoxycholate, $1 \%$ NP- $40,1 \mathrm{~mm}$ sodium orthovanadate, $20 \mu \mathrm{g} / \mathrm{ml}$ pepstatin, $20 \mu \mathrm{g} / \mathrm{ml}$ aprotinin, and $20 \mu \mathrm{g} / \mathrm{ml}$ leupeptin). The homogenate was centrifuged at $16,000 \times g$ for $20 \mathrm{~min}$, and the supernatant was used. To prepare cellular extracts, CHO-rSERT cells were transiently transfected with various plasmids. Forty-eight hours after transfection, cells were lyzed in ice-cold lysis buffer supplemented with a mixture of proteinase inhibitors (Complete; Roche Diagnostics). The protein concentration was determined using a DC Protein Assay kit (BioRad). Samples (10-100 $\mu \mathrm{g}$ of protein) were boiled in Laemli's sample buffer (125 mm Tris-HCl, pH 6.8, 10\% 2-mercaptoethanol, 4\% SDS, $10 \%$ sucrose, and $0.004 \%$ bromophenol blue), separated on a polyacrylamide gel, and subsequently transferred to polyvinylidene difluoride (PVDF) membranes (Millipore Corporation). The membranes were blocked with a Detector Block kit (Kirkegaard and Perry Laboratories) and probed with a primary antibody. Membranes were washed with the washing buffer (50 mm Tris-HCl, pH 7.4, 0.05\% Tween 20, and $150 \mathrm{~mm}$ $\mathrm{NaCl}$ ) and subsequently incubated with a horseradish peroxidaseconjugated secondary antibody. The immune complexes were detected by ChemiDoc XRS (Bio-Rad) based on chemiluminescence (ECL kit; GE Healthcare). The band intensities were analyzed by densitometry using the ATTO Densitograph Software Library Lane Analyzer (ATTO). To normalize each sample, membranes were stripped with stripping buffer (100 mм 2-mercaptoehanol, 2\% SDS, and $62.5 \mathrm{~mm}$ Tris-HCl, pH 6.7) at $50^{\circ} \mathrm{C}$ for $30 \mathrm{~min}$, and the amount of $\beta$-actin protein was determined using the antibody and chemiluminescence.

The primary antibodies included the following: a rabbit antiMAGE-D1 (1:1000; Millipore), a rabbit anti-MAGE-D2 (1:500; Proteintech), a rabbit anti-MAP2 (1:1000; Millipore), a mouse anti-glial fibrillary acidic protein (GFAP) (1:1000; Millipore), a rabbit anti-SERT (1:1000; Millipore), a rabbit anti-monoamine oxidase A (MAO-A) (1: 500; Santa Cruz Biotechnology), a rabbit anti-tryptophan hydroxylase 2 (TPH2) (1:500; Millipore), and a rabbit anti-HA tag (1:500; Medical \& Biological Laboratories). The secondary antibodies, used at a dilution of 1:2000, were horseradish peroxidase-linked anti-mouse or anti-rabbit IgG (Kirkegaard and Perry Laboratories).

\section{Immunoprecipitation}

Tissue and cellular lysates ( $0.5 \mathrm{mg}$ of protein) were subjected to immunoprecipitation with HA or SERT antibody and Dynabeads protein A (Invitrogen). The immunoprecipitate was boiled in Laemli's sample buffer, separated on a polyacrylamide gel, and subsequently transferred to a PVDF membrane. The membranes were blocked and probed with HA antibody or SERT antibody and detected by the chemiluminescence.

\section{Detection of ubiquitinylated protein}

Detection of ubiquitinylated protein was conducted using the agaroseimmobilized p62-derived UBA domain (UbiQapture-Q kit; Enzo Life Sciences). Equal amounts of protein were incubated with beads chemically coupled to the UBA domain. Beads were washed with cold PBS, and the supernatants were discarded. Proteins were eluted in Laemli's sample buffer, separated on a polyacrylamide gel, and subsequently transferred to a PVDF membrane. The membranes were blocked and probed with SERT antibody, and the presence of ubiquitinylated protein was detected by the chemiluminescence

\section{Immunofluorescence and Nissl staining}

Histological procedures were performed as described previously (Mouri et al., 2010) with a minor modification. Mice were anesthetized with urethane (1 g/kg, i.p.) and perfused transcardially with ice-cold PBS, followed by $4 \%$ paraformaldehyde in PBS. The brains were removed, postfixed in the same fixative for $2 \mathrm{~h}$, and then soaked in $20 \%(\mathrm{w} / \mathrm{v})$ sucrose in PBS. Coronal sections $15 \mu \mathrm{m}$ thick were cut with a Cryostar HM560 cryostat (Microm International). For immunocytochemistry, cells were plated at low density on Lab-Tek Chamber Slides (BD Bioscience). Forty-eight hours after transfection, cells were washed with PBS and fixed with $4 \%$ paraformaldehyde prepared in PBS. For immunostaining, the samples were treated with $4 \%$-BlockAce (Dainippon Pharmaceutical) dissolved in $0.3 \%$ Triton X-100/TBS. The primary antibodies, such as a rabbit anti-MAGE-D1 (1:500; Millipore), a mouse anti-neuron-specific nuclear antigen (NeuN) (1:500; Millipore), a mouse anti-GFAP (1:500; Millipore), and a mouse anti-SERT (1:500; Millipore), were applied to the brain slices. Fluorescently conjugated secondary antibodies (Alexa Fluor 488 and 546; Invitrogen) were used for detecting chromagen. For Nissl staining, sections were cut at $40 \mu \mathrm{m}$ intervals, and staining was done according to the standard procedure (Murai et al., 2007). Images were acquired with a confocal microscope (LSM510; Carl Zeiss) and a light microscope (Axiocam HRc; Carl Zeiss).

\section{Amounts of serotonin and its metabolite}

Serotonin metabolism was measured as described previously (Kasahara et al., 2006). The amounts of serotonin and its metabolite [5hydroxyindoleacetic acid (5-HIAA)] were determined using an HPLC system (HTEC-500; Eicom). Each frozen brain sample was weighed and homogenized with an ultrasonic processor in $0.2 \mathrm{M}$ perchloric acid containing isoproterenol as an internal standard. The homogenates were placed on ice and centrifuged at 20,000 $\times g$ for $15 \mathrm{~min}$. The supernatants were mixed with $1 \mathrm{~m}$ sodium acetate to adjust the $\mathrm{pH}$ to 3.0 and injected into an HPLC system equipped with a reversed-phase ODS column (Eicompak SC-5ODS; Eicom) and an electrochemical detector. The turnover of serotonin was assessed by the ratio of 5-HIAA/serotonin.

\section{In vivo microdialysis}

In vivo microdialysis was performed as described previously (Mouri et al., 2007b). Mice were anesthetized with sodium pentobarbital (40 mg/ $\mathrm{kg}$, i.p.) before stereotaxic implantation of a guide cannula (AG-6; Eicom) into the ventral hippocampus $(-2.8 \mathrm{~mm}$ anteroposterior, \pm 3.0 $\mathrm{mm}$ mediolateral from bregma, $-2.0 \mathrm{~mm}$ dorsoventral from the skull). One day after the operation, a dialysis probe (AI-4-2; $2 \mathrm{~mm}$ membrane length; Eicom) was inserted through the guide cannula and perfused with artificial CSF (in mM: $147 \mathrm{NaCl}, 4 \mathrm{KCl}$ and $2.3 \mathrm{CaCl}_{2}$ ) at a flow rate of 1 $\mu \mathrm{l} / \mathrm{min}$. The dialysate was collected every $20 \mathrm{~min}$. Dialysates were analyzed by HPLC with an electrochemical detector (HTEC-500; Eicom). Three time points were chosen for measurements to establish baseline levels of extracellular neurotransmitter. For depolarization stimulation, Ringer's solution containing $50 \mathrm{~mm} \mathrm{KCl}$ was delivered through the dialysis probe for $20 \mathrm{~min}$ to measure the $\mathrm{K}^{+}$-evoked release of serotonin.

\section{Real-time reverse transcription- $P C R$}

The prefrontal cortex of each test mouse was homogenized, and total RNA was extracted using an RNeasy total RNA isolation kit (Qiagen) and converted into cDNA using a SuperScript III First-Strand Synthesis System for RT-PCR kit (Invitrogen). The primers used were as follows: for SERT (GenBank accession number AF013604), forward primer, 5'-GG ATTTCCTCCTGTCTGTCATTGG- $3^{\prime}$, reverse primer, $5^{\prime}$-CCACCATT CTGGTAGCATATGTAGG-3' , and TaqMan probe, $5^{\prime}$-CCGTGGACCT GGGCAACATCTGGC-3'; for $\beta$-actin (GenBank accession number NM007393), forward primer, 5'-GGGCTATGCTCTCCCTCACG-3', reverse primer, 5'-GTCACGCACGATTTCCCTCTC-3', and TaqMan probe, 5'-CCTGCGTCTGGACCTGGCTGGC-3'. PCRs were performed using the Platinum TaqDNA polymerase (Invitrogen). The reaction profile consisted of a first round at $95^{\circ} \mathrm{C}$ for $3 \mathrm{~min}$ and then 40 cycles of denaturation at $95^{\circ} \mathrm{C}$ for $10 \mathrm{~s}$, annealing at $60^{\circ} \mathrm{C}$ for $34 \mathrm{~s}$, and extension at $72^{\circ} \mathrm{C}$ for $1 \mathrm{~min}$, with a final extension reaction performed at $72^{\circ} \mathrm{C}$ for $10 \mathrm{~min}$ in an iCycle iQ Detection System (Bio-Rad). To standardize the quantification, $\beta$-actin was calculated with SERT simultaneously. Expression levels were calculated by the $\Delta \Delta \mathrm{Ct}$ method.

\section{Serotonin uptake assay}

CHO-rSERT cells were washed three times with Krebs'-Ringer'sHEPES-buffered solution (KRH) (in mM: $125 \mathrm{NaCl}, 5.2 \mathrm{KCl}, 1.2$ 
A

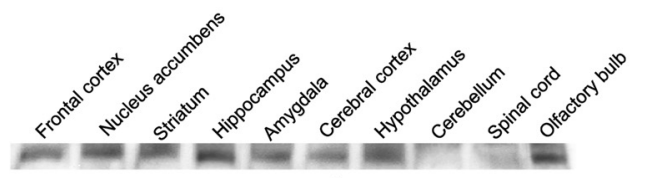

B
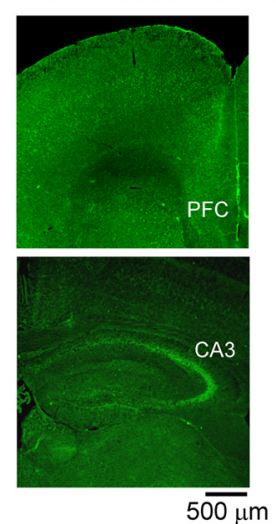

D

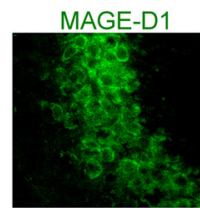

MAGE-D1

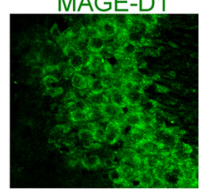

C
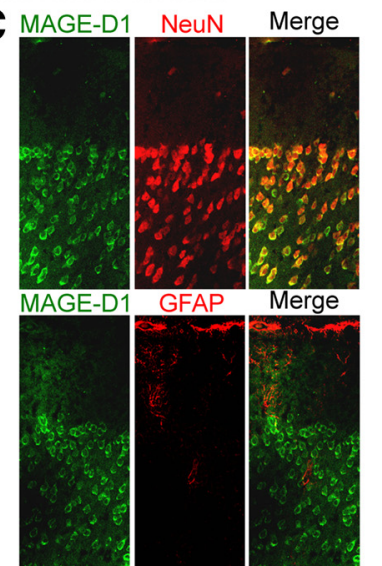

$\int^{2}$

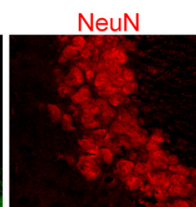

GFAP
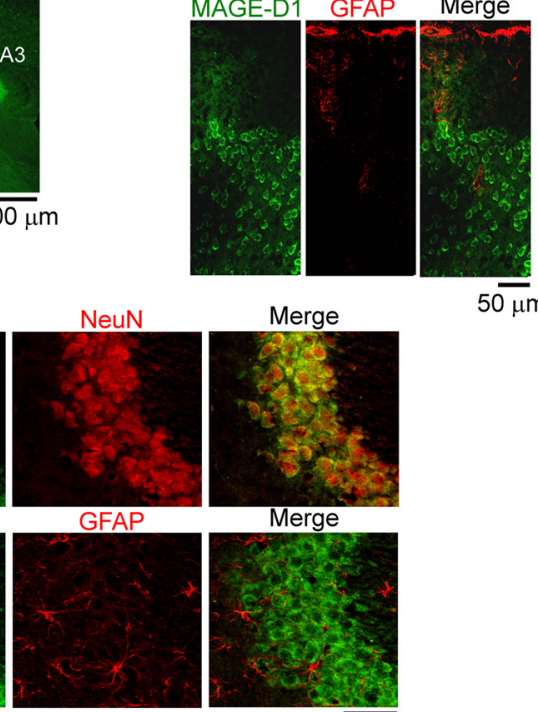

$50 \overline{\mathrm{mm}}$

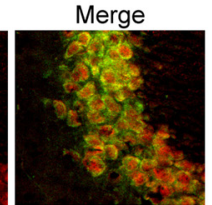

Merge
E
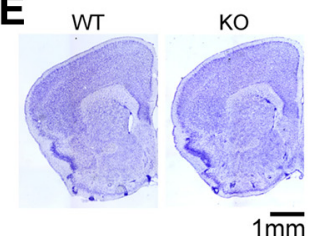

$F$
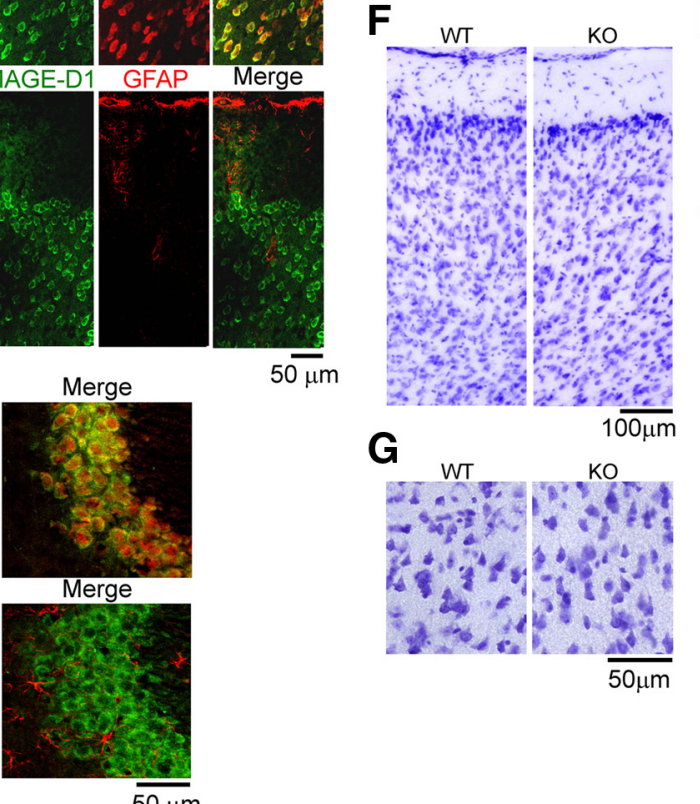

G

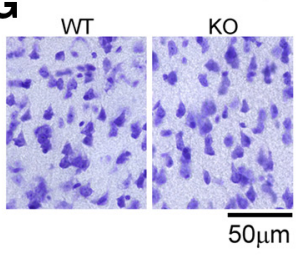

H

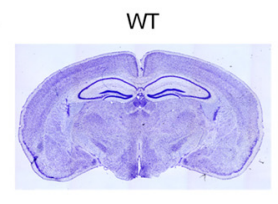

WT
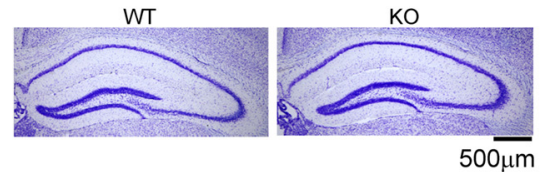

J

CA1

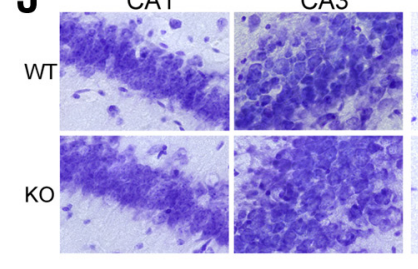

DG
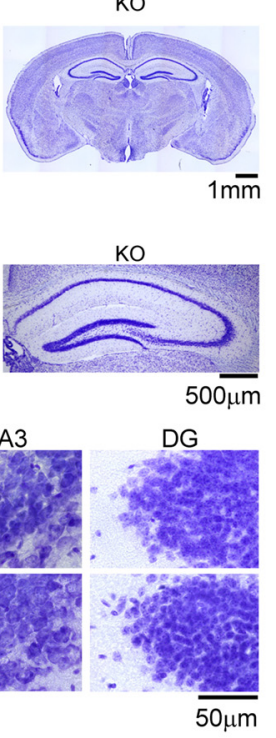

Figure 2. Histological appearance of the MAGE-D1 K0 mice. $\boldsymbol{A}$, Expression of MAGE-D1 protein in various areas of the brain: MAGE-D1 expression in the brain of wild-type mice was determined by Western blotting using anti-MAGE-D1. B, Localization of MAGE-D1 in the prefrontal cortex and hippocampus: confocal immun ofluorescent images obtained from coronal sections from wild-type mice. $\boldsymbol{C}, \boldsymbol{D}$, Higher-magnitude images of the prefrontal cortical layer and hippocampal CA3 region, respectively. Double-labeling fluorescence photomicrographs for MAGE-D1 (green) and NeuN or GFAP (red). The MAGE-D1-immunopositive cells were colocalized to cells positive for NeuN, a marker of neuronal cells, but not to cells positive for GFAP, a marker of astrocytes. $\boldsymbol{E}-\boldsymbol{J}$, Nissl staining in the MAGE-D1 K0 and wild-type mice: slices of the prefrontal cortex (E-G) and hippocampus $(\boldsymbol{H}-\boldsymbol{J})$ obtained from the MAGE-D1 K0 mice showed no gross $(\boldsymbol{E}, \boldsymbol{H})$ or layered structural $(\boldsymbol{F}, \boldsymbol{I})$ abnormalities. A higher-magnitude image of the prefrontal cortical layer $(\boldsymbol{G})$ and hippocampal $C A 1, C A 3$, and DG regions $(\boldsymbol{J})$; there were no morphological changes to neuronal cells or astrocytes in the MAGE-D1 K0 mice. WT, Wild-type mice.

$\mathrm{CaCl}_{2}, 1.4 \mathrm{MgSO}_{4}, 1.2 \mathrm{KH}_{2} \mathrm{PO}_{4}, 5$ glucose, and 20 HEPES, pH 7.3) and incubated for $10 \mathrm{~min}$ at $37^{\circ} \mathrm{C}$ with $10 \mathrm{~nm}\left[{ }^{3} \mathrm{H}\right]$ serotonin, as described previously (Sogawa et al., 2007). Ascorbic acid (100 $\mu \mathrm{M})$ and pargyline $(50 \mu \mathrm{M})$ were added to the incubation solution during serotonin uptake assays. After the removal of excess radioligands, the cells were washed three times rapidly with ice-cold $\mathrm{KRH}$, and radioactivity remaining in the cells was extracted with $\mathrm{NaOH}(1 \mathrm{M})$ and measured by liquid scintillation spectrometry. For kinetic analysis, cells were incubated in $\mathrm{KRH}$ containing $10 \mathrm{nM}\left[{ }^{3} \mathrm{H}\right]$ serotonin and $0.1-10 \mu \mathrm{M}$ unlabeled serotonin.

\section{Statistic analysis}

All results were expressed as the mean \pm SEM for each group. The difference between groups was analyzed with a one-way, two-way, or repeated-measures ANOVA, followed by the Bonferroni's/Dunn's multiple range test. The Student's $t$ test was used to compare two sets of data.

\section{Results}

\section{General characteristics}

The genotype for the MAGE-D1 locus was assessed by Southern blotting and PCR (Fig. 1B,C). MAGE-D1 KO mice were confirmed to lack MAGE-D1 protein by Western blotting (Fig. $1 D$ ). The MAGE-D1 KO mice, born normally according to Mendelian inheritance, were healthy (no gross abnormality or abnormal lifespan) and showed no changes in physical characteristics (body weight, or appearance of fur and whiskers) at 3 months old (Fig. 1E).

\section{Normal histological appearance}

Western blotting with the MAGE-D1 antibody was used to examine the distribution of MAGE-D1 protein in the CNS of adult mice (Fig. 2A). MAGE-D1 was highly expressed in the various brain areas (frontal cortex, nucleus accumbens, striatum, hippocampus, amygdala, cerebral cortex, hypothalamus, and olfactory bulb) but only slightly in the cerebellum and spinal cord (Fig. $2 A)$. Strong immunoreactivity to MAGE-D1 was observed in the prefrontal cortex and hippocampal CA3 regions (Fig. $2 B$ ). In higher-resolution image, MAGE-D1 immunoreactivity merged with that to NeuN, a neuronal marker, but sparsely to GFAP, an astrocyte marker in the prefrontal cortex (Fig. 2C) and CA3 (Fig. $2 D)$ regions. Nissl staining showed neither gross (Fig. 2E, $H$ ), layered-structural (Fig. 2F,I) nor cellular-morphological (Fig. $2 G, J$ ) abnormality in the prefrontal cortex (Fig. $2 E-G$ ) or hippocampus (Fig. $2 \mathrm{H}-\mathrm{J}$ ). 
Decrease in activity in home cage and exploratory behavior in novel environment To investigate the roles of MAGE-D1 in emotional and cognitive functions, mice were subjected to several types of neurobehavioral tests. First, we measured circadian activity and exploratory behavior (Fig. $3 A, B$ ). MAGE-D1 KOs and their littermate wild-type mice displayed a normal circadian rhythm [i.e., their activity was reduced during the light phase (8:00 A.M. to 8:00 P.M.) and then increased markedly at the beginning of the dark phase] (Fig. 3A: repeated-measures ANOVA, $F_{\text {MAGE-D1 KO }(1,918)}=81.58, p<$ $0.01 ; F_{\text {time }}(51,918)=20.68, p<0.01$; $F_{\text {MaGe-di кo }} \times$ time $\left.(51,918)=2.88, p<0.01\right)$. However, MAGE-D1 KO mice showed a greater decrease in activity than wild-type mice during both dark and light phases (Fig. 3B: Student's $t$ test, $\operatorname{dark}(1), t_{(18)}=$ $1.52, p>0.1$; light, $t_{(18)}=2.56, p<0.05$; $\left.\operatorname{dark}(2), t_{(18)}=2.71, p<0.05\right)$. Rodents generally display an increase in exploratory activity in a novel environment, and the activity is subsequently reduced as they habituate to the environment. Interestingly, MAGE-D1 KO mice also displayed a greater decrease in locomotor activity than wild-type mice did during the first 0-9 h (habituation phase, 11:00 A.M. to 8:00 P.M.) of the test (Fig. 3B: Student's $t$ test, $\left.t_{(18)}=2.54, p<0.05\right)$, suggesting a decrease in exploration of the novel environment. To confirm these possibilities, the MAGE-D1 KO mice were placed in a novel apparatus, and their locomotor activity was measured (Fig. 3C,D). The MAGE-D1 KO mice were also hypoactive in the novel apparatus (Fig. 3C: repeatedmeasures ANOVA, $F_{\text {MAGE-D1 KO }(1,144)}=$ $6.24, p<0.01 ; F_{\text {time }(8,144)}=26.88, p<$ $0.01 ; F_{\text {MAGE-D1 ко } \times \text { time }(8,144)}=1.13, p>0.1$; Fig. $3 D$ : Student's $t$ test, $t_{(18)}=2.50, p<$ $0.01)$. To determine whether the decrease in activity of the MAGE-D1 KO mice could be attributed to motor deficits, an observation of physical motor ability or coordination was conducted by rotarod test. There was no difference in performance of the test between two groups, indicating normal motor coordination and motor learning in the MAGE-D1 KO mice (Fig. 3E: repeated-measures ANOVA, $F_{\text {MAGE-D1 Ко (1,72) }}=0.09, p>0.1 ; F_{\text {trial }(4,72)}=9.09, p<0.01 ; F_{\text {MAGE- }}$ D1 KO $\times$ trial $(4,72)=1.76, p>0.1)$.

\section{Normal anxiety-like behavior}

In the open-field test, there was a decreasing tendency in case of horizontal activity (distance moved) and significant decrease in vertical activity (rearing) in the MAGE-D1 KO mice (Fig. $4 B$ : Student's $t$ test, $t_{(18)}=2.04, p>0.05$; Fig. $4 C$ : Student's $t$ test, $t_{(18)}$ $=2.91, p<0.01)$. However, a decrease in time spent in the center of the open field, an indicator of increased anxiety-like behavior (Crawley, 1999), was not observed as much in the MAGE-D1 KO mice compared with the wild-type mice (Fig. $4 D$ : Student's $t$ test,
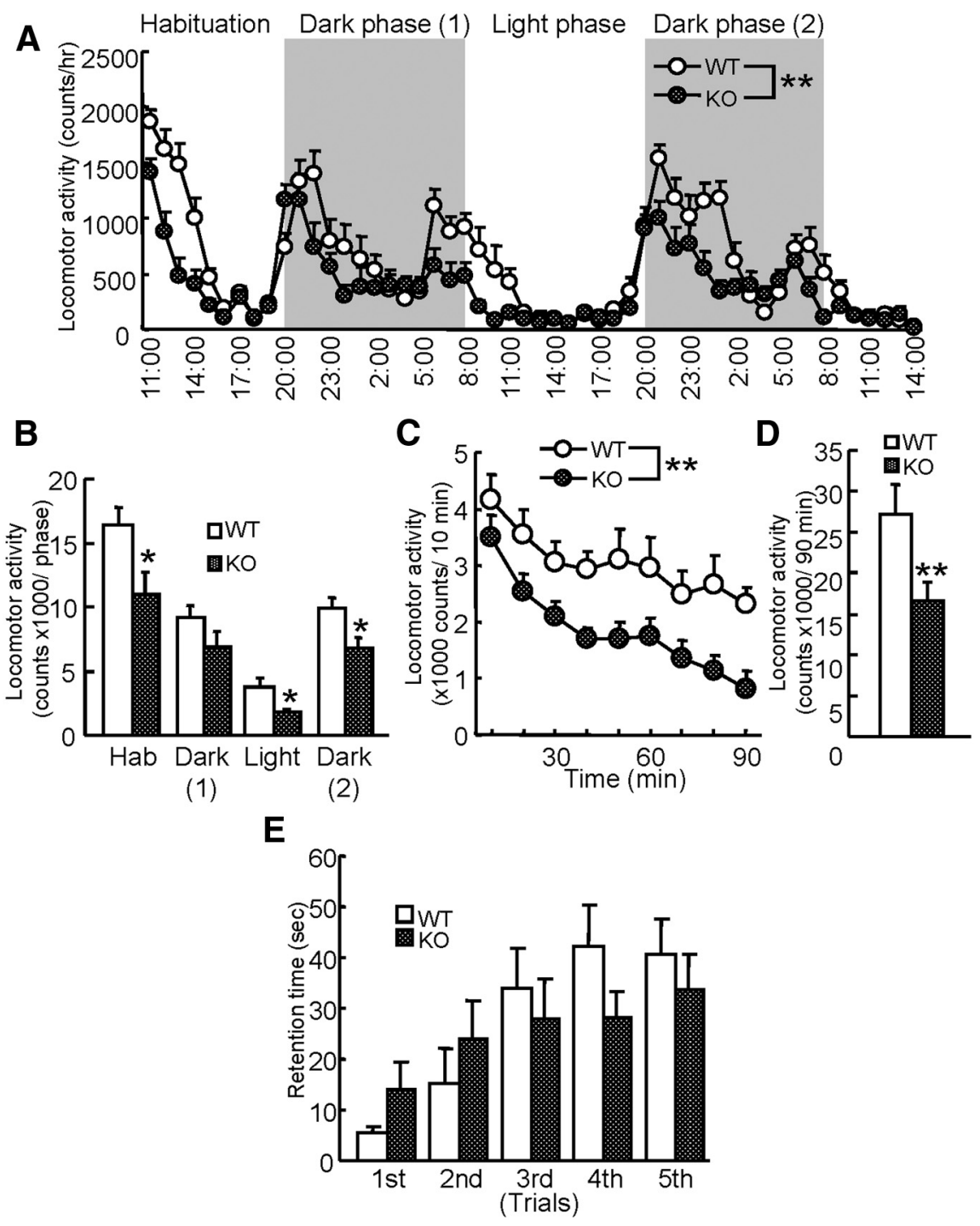

Figure 3. Decrease in activity in home cages and exploratory behavior in a novel environment among the MAGE-D1 KO mice. $\boldsymbol{A}, \boldsymbol{B}$, Locomotor activity in the home cages of the MAGE-D1 K0 mice. MAGE-D1 K0 and wild-type mice were placed in $(12 \mathrm{~h})$ are indicated by white and gray backgrounds, respectively. C, D, Locomotor activity in a novel environment among the MAGE-D1 KO mice. Locomotor activity in a novel environment was measured every $10 \mathrm{~min}$ for $90 \mathrm{~min}$. $\boldsymbol{E}$, Motor function mean \pm SEM $(n=10) .{ }^{*} p<0.05,{ }^{* *} p<0.01$ versus wild-type mice. WT, Wild-type mice; Hab, habituation. Dark (1), dark phase 1; Light, light phase; Dark (2), dark phase 2.

center, $t_{(18)}=0.15, p>0.1$; middle, $t_{(18)}=-0.52, p>0.1$ outside, $\left.t_{(18)}=0.46, p>0.1\right)$. Furthermore, there was no obvious difference in anxiety-like behaviors (starting latency to move to other areas, frequency of grooming, urination, and defecation) between MAGE-D1 KO and wild-type mice (Table 1). To further investigate anxiety-like behavior in the MAGE-D1 KO mice, the mice were subjected to the elevated plus maze test, which also measures anxiety-like behavior in mice based on their natural aversion to open and elevated areas (Fernández Espejo, 1997). The percentages for entries into the open arm were similar for both the MAGE-D1 KO mice and wild-type mice (Fig. 4 E: Student's $t$ test, $\left.t_{(18)}=-0.48, p>0.1\right)$. The MAGE-D1 KO mice consistently displayed a pronounced decrease in activity and exploratory behavior, as shown by the decrease in total arm entries (Fig. 4 F: Student's $t$ test, $\left.t_{(18)}=2.39, p<0.05\right)$. Although it is possible that the decrease in explorative activity of the MAGE-D1 KO mice could be attributable 
A

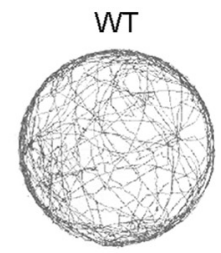

B

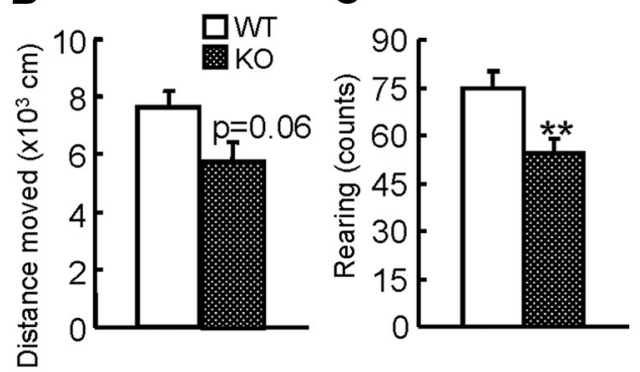

D
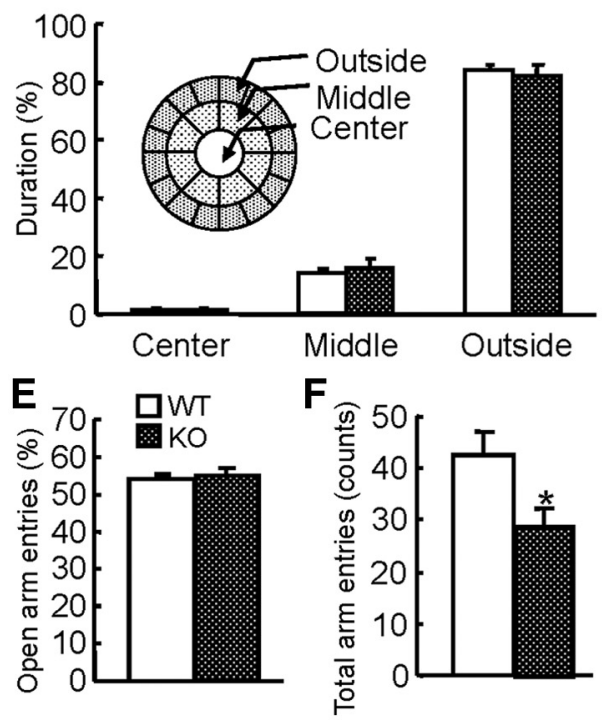

Figure 4. Normal anxiety-like behaviors in the MAGE-D1 KO mice. $A-D$, Exploratory and anxietylike behaviors in an open field among the MAGE-D1 KO. MAGE-D1 KO and wild-type male mice were placed in an open field, and their behavior was assessed by representative exploring paths $(A)$, distance moved $(\boldsymbol{B})$, number of instances of rearing $(\boldsymbol{C})$, and percentage of time spent in each area $(\boldsymbol{D})$ for $10 \mathrm{~min} . \boldsymbol{E}, \boldsymbol{F}$, Exploratory and anxiety-like behaviors in the MAGE-D1 KO mice in an elevated plus maze. MAGE-D1 KO and wild-type males were placed in an elevated plus maze, and their behavior was assessed by measuring the percentage of time spent in the open arms $(\boldsymbol{E})$ and the number of total arm entries $(\boldsymbol{F})$ for $10 \mathrm{~min}$. Each column represents the mean $\pm \operatorname{SEM}(n=10) .{ }^{*} p<0.05,{ }^{* *} p<0.01$ versus wild-type mice. WT, Wild-type mice.

Table 1. Exploratory behavior in open-field test of MAGE-D1 KO mice

\begin{tabular}{llll}
\hline & WT & KO & Results \\
\hline Starting latency (s) & $5.9 \pm 0.7$ & $7.0 \pm 0.8$ & Student's $t$ test, $t_{(18)}=-1.01, p=0.33$ \\
Grooming (n) & $4.7 \pm 0.5$ & $4.5 \pm 0.4$ & Student's $t$ test, $t_{(18)}=0.29, p=0.77$ \\
Defecation (n) & $3.6 \pm 0.6$ & $2.6 \pm 0.7$ & Student's $t$ test, $t_{(18)}=1.10, p=0.29$ \\
Urination (n) & $0.6 \pm 0.2$ & $0.6 \pm 0.2$ & Student's $t$ test, $t_{(18)}=0.00, p=1.00$ \\
\hline
\end{tabular}

WT, Wild-type mice. Values are the means $\pm \operatorname{SEM}(n=10)$.

to novelty-induced anxiety-like behavior (Prut and Belzung, 2003), MAGE-D1 KO mice showed normal anxiety behavior in these tests.

Social withdrawal, reduced motivation, and anhedonia

To address whether a decrease in exploratory behavior of the MAGE-D1 KO mice could be observed not only in an unfamiliar
A

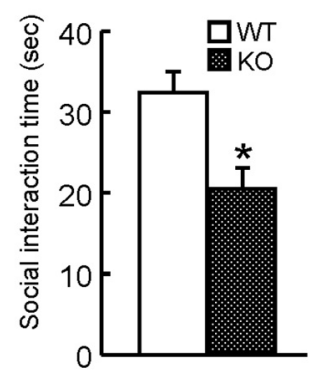

C

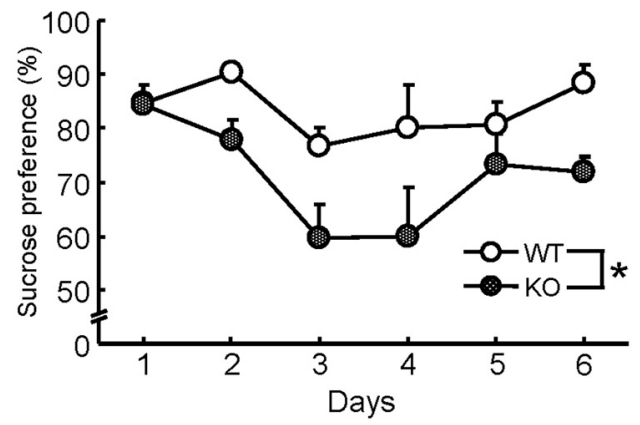

Figure 5. Social withdrawal, enhanced despair, and anhedonia in the MAGE-D1 KO mice. $\boldsymbol{A}$, Social interaction in the MAGE-D1 K0 mice. MAGE-D1 KO and wild-type mice were placed in an apparatus with an unfamiliar mouse, and their social interaction was measured for $10 \mathrm{~min}$. $\boldsymbol{B}$, Motivation in inescapable water-contained cylinder in MAGE-D1 KO mice. MAGE-D1 KO and wild-type mice were placed in a water-contained cylinder, and their immobility time was measured for $10 \mathrm{~min}$. C, Sucrose preference among the MAGE-D1 KO mice. MAGE-D1 KO and wildtype mice were individually housed and the percentage of total liquid consumed that was $1 \%$ sucrose solution was measured for $6 \mathrm{~d}$. Each column represents the mean \pm SEM $(n=10)$. ${ }^{*} p<0.05$ versus wild-type mice. WT, Wild-type mice.

environment but also in relation to other mice, mice were subjected to a social interaction test. During a 10 min social interaction test, the total duration of social interaction of the MAGE-D1 KO mice with unfamiliar C57BL/6J mice was significantly shorter than that of wild-type mice (Fig. $5 A$ : Student's $t$ test, $t_{(18)}=2.40$, $p<0.05)$.

It has been proposed that a decrease in locomotor activity in the home cage and social withdrawal could be used as behavior models of fatigue (or loss of energy) and diminished interest, respectively; both are symptoms of major depression (Cryan and Holmes, 2005). Decreased locomotor activity is observed in some animal models of depression as a symptom of psychomotor retardation related to diminished interest (Willner, 1991; Overstreet, 1993). It is possible, then, that these noticeable behaviors in the MAGE-D1 KO mice could be defined as depressive behaviors. To investigate this, mice were subjected to a forced swimming test, which is a wellestablished paradigm for assessing despair-related behaviors in rodents. The test results indicated that the time spent in an immobile posture was significantly longer in the MAGE-D1 KO than in the wild-type mice (Fig. $5 B$ : Student's $t$ test, $t_{(18)}=$ $-2.88, p<0.05)$.

Anhedonia is also hallmark symptom of depression (Willner et al., 1987). In addition to the above tests, MAGE-D1 KO mice were subjected to a sucrose preference test, a behavioral paradigm that measures a mouse's responsiveness to a natural reward (Willner et al., 1987). When a MAGE-D1 KO mouse was presented with two drinking bottles, one containing water and the other containing $1 \%$ sucrose, the mouse consumed significantly 

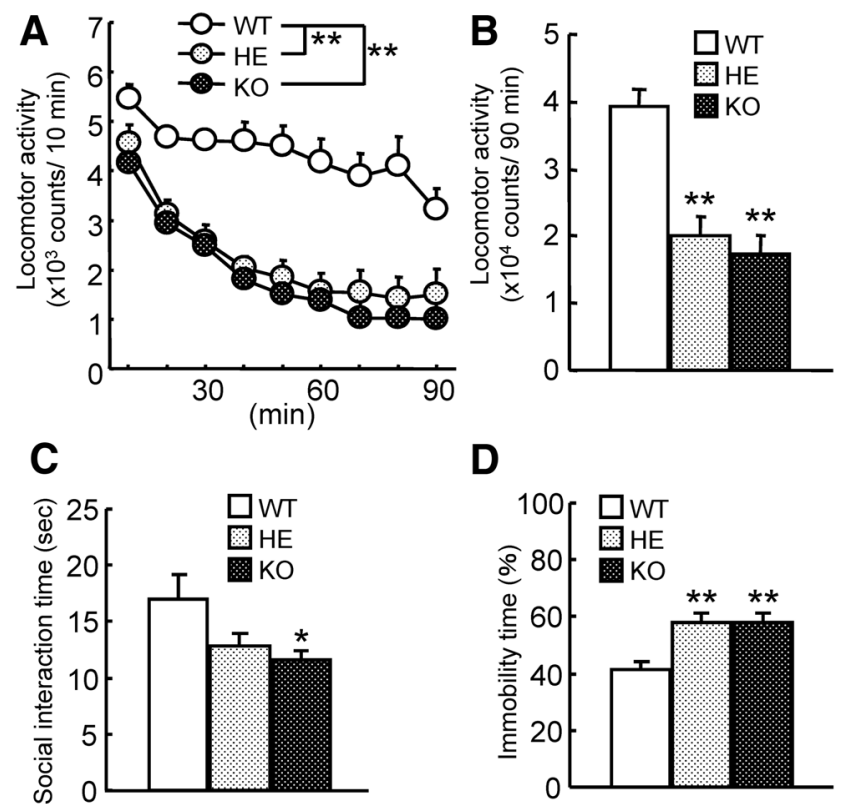

Figure 6. Depression-like behavior in female MAGE-D1 K0 mice. $A, B$, Locomotor activity of female MAGE-D1 heterozygous and K0 mice in a novel environment in a locomotor test. C, Social interaction of female MAGE-D1 heterozygous and K0 mice in a social interaction test. $\boldsymbol{D}$, Motivation of female MAGE-D1 heterozygous and $\mathrm{KO}$ mice in a forced swimming test. Each column represents the mean $\pm \operatorname{SEM}(n=12) .{ }^{*} p<0.05,{ }^{* *} p<0.01$ versus wild-type mice. WT, Wild-type mice; HE, MAGE-D1 heterozygous mice.

less of the sucrose solution relative to the water than did wild-type mice (Fig. 5C: repeated-measures ANOVA, $F_{\text {MAGE-D1 KO }(1,119)}=$ $6.02, p<0.05 ; F_{\mathrm{day}(5,119)}=6.87, p<0.01 ; F_{\mathrm{MAGE}-\mathrm{D} 1 \mathrm{KO} \times \text { day }(5,119)}=$ $1.96, p>0.05$ ), which suggested a lower responsiveness to rewards.

Taking the above results together, it can be concluded that the MAGE-D1 KO mice used in this study exhibited depression-like behavior. The next step was to investigate the possibility of differences in such behavior based on sex. There is epidemiological and clinical evidence that approximately twice as many women as men are diagnosed with major depression (Kuehner, 2003; Leach et al., 2008). Because the Maged1 gene is on the X chromosome, MAGE-D1 heterozygous KO female but not male mice are available. To investigate sex-related differences in depression-like behavior of MAGE-D1 KO mice, female MAGE-D1 heterozygous and KO mice were subjected to behavioral tasks. The results were that female MAGE-D1 heterozygous and KO mice also behaved similarly to male $\mathrm{KO}$ mice in all the tasks: the spontaneous activity test (Fig. $6 \mathrm{~A}$ : repeated-measures ANOVA, $F_{\text {MAGE-D1 KO }(2,264)}=18.39, p<0.01$; $F_{\text {time }(8,264)}=38.32, p<0.01 ; F_{\text {MAGE-D1 KO } \times \text { time }(16,264)}=2.15$, $p<0.01$; Fig. $6 B$ : one-way ANOVA, $\left.F_{(2,33)}=18.39, p<0.01\right)$, the social interaction test (Fig. 6C: one-way ANOVA, $F_{(2,33)}=4.93, p<$ 0.05 ), and the forced swimming test (Fig. 6D: one-way ANOVA, $\left.F_{(2,33)}=7.63, p<0.01\right)$. There was no sex-based difference in the depression-like behavior induced by MAGE-D1 deficiency.

To investigate the physiological roles of MAGE-D1 after brain development, we investigated the effects of MAGE-D1 knockdown in the adult prefrontal cortex on emotional functions by injecting siRNA (Fig. 7A). MAGE-D1 siRNA was found to significantly decrease MAGE-D1 expression in the prefrontal cortex (Fig. 7B: Student's $t$ test, $t_{(9)}=4.04, p<0.01$ ). To investigate specificity of MAGE-D1 siRNA, we investigated the effect of MAGE-D1 siRNA on the expression level of the other type II MAGE family protein MAGE-D2, the dendritic marker MAP2, and GFAP in the frontal cortex. The levels of protein were not affected by MAGE-D1 siRNA (data not shown). Mice infused with MAGE-D1 siRNA showed a decrease in locomotor activity in a novel environment (Fig. 7C: Student's $t$ test, $t_{(9)}=2.42, p<$ 0.05 ) and in social interaction (Fig. 7D: Student's $t$ test, $t_{(9)}=$ $4.59, p<0.01)$, increased immobility time in the tail suspension test (Fig. $7 E$ : Student's $t$ test, $t_{(9)}=-2.32, p<0.05$ ) but not in the forced swimming test (Fig. $7 F$ : Student's $t$ test, $t_{(9)}=0.71, p>0.1$ ), and a decrease in sucrose preference (Fig. $7 G$ : repeated-measures ANOVA, $F_{\text {MAGE-D1 siRNA }(1,95)}=11.02, p<0.01 ; F_{\text {day }(5,95)}=3.11$, $\left.p<0.05 ; F_{\text {MAGE-D1 siRNA } \times \text { day }(5,95)}=0.63, p>0.1\right)$. Although there was no difference in the duration of immobility in the forced swimming test, MAGE-D1 knockdown in the adult prefrontal cortex replicated all of the other depression-like behavior in the MAGE-D1 KO mice.

\section{Normal cognitive functions}

There was no difference between wild-type mice and MAGE-D1 KO mice in short-term memory indicated by spontaneous alternation behavior in the Y-maze (Fig. 8 A: Student's $t$ test, $t_{(18)}=0.04, p>$ 0.1 ), visual recognition memory indicated by exploratory preference to a novel object in a novel object recognition test (Fig. 8C: repeated-measures ANOVA, $F_{\text {MAGE-D1 KO }(1,18)}=4.38, p>0.05$; $F_{\text {session }(1,18)}=33.16, p<0.01 ; F_{\text {MAGE-D1 KO } \times \text { session }(1,18)}=0.09$, $p>0.1)$, latent learning indicated by finding latency in the water finding test (Fig. $8 \mathrm{~F}$ : two-way ANOVA, $F_{\mathrm{MAGE}-\mathrm{D} 1 \mathrm{KO}(1,36)}=1.97$, $p>0.1 ; F_{\text {training }(1,36)}=22.13, p<0.01 ; F_{\text {MAGE-D1 } \mathrm{KO} \times \operatorname{training}(1,36)}=$ $0.05, p>0.1)$, or associative learning indicated by contextual and cue-induced freezing responses in the conditioned fear learning test (Fig. 8G: contextual learning: repeated-measures ANOVA, $F_{\text {MAGE-D1 KO }(1,18)}=0.06, p>0.1 ; F_{\text {conditioning }(1,18)}=$

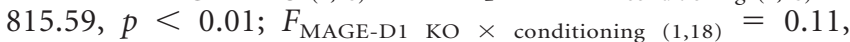
$p>0.1$; Fig. $8 H$ : cued learning: repeated-measures ANOVA, $F_{\text {MAGE-D1 KO }(1,18)}=1.05, p>0.1 ; F_{\text {conditioning }(1,18)}=$ 593.91, $p<0.01 ; F_{\text {MAGE-D1 KO } \times \text { conditioning }(1,18)}=1.86, p>$ $0.1)$. These results indicated that MAGE-D1 KO mice have normal cognitive functions. MAGE-D1 KO mice consistently showed low ambulation in the Y-maze (Fig. 8 B; Student's $t$ test, $t_{(18)}=5.06, p<0.01$ ) and the novel-object recognition test (Fig. $8 E$; repeated-measures ANOVA, $F_{\text {MAGE-D1 KO }(1,18)}=10.36, p<$ $0.01 ; F_{\text {session }(1,18)}=210.19, p<0.01 ; \mathrm{F}_{\text {MAGE-D1 } \mathrm{KO} \times \operatorname{session}(1,18)}=$ $8.15, p<0.05)$.

\section{Antidepressants reverse depression-like behavior in the MAGE-D1 KO mice}

From the above results, we confirmed that MAGE-D1 KO mice satisfied the condition of the face validity as animal model of depression. It is well known that antidepressants decrease the duration of immobility in a forced swimming test (David et al., 2003). To confirm their predictive validity as animal model of depression, we studied the effect of antidepressants on the behavioral changes in MAGE-D1 KO mice to determine whether behavioral changes observed in the MAGE-D1 KO mice are related to depression-like behavior. Acute administration of sertraline or imipramine, two chemically distinct antidepressants used widely in humans, decreased the duration of immobility in the MAGE-D1 KO mice in a forced swimming test (Fig. 9A: sertraline, two-way ANOVA, $F_{\text {MAGE-D1 KO }(1,60)}=18.64, p<0.01 ; F_{\text {sertraline }(2,60)}=$ $3.98, p<0.05 ; F_{\text {MAGE-D1 KO } \times \text { sertraline }(2,60)}=0.91, p>0.1$; imipramine, two-way ANOVA, $F_{\text {MAGE-D1 KO }(1,44)}=7.76, p<0.01$; $F_{\text {imipramine }(2,44)}=3.96, p<0.05 ; F_{\text {MAGE-D1 KO } \times \text { imipramine }(2,44)}=$ $2.09, p>0.1)$. In addition, sertraline attenuated a decrease in social interaction with an unfamiliar mouse (Fig. 9B: sertraline, twoway ANOVA, $F_{\text {MAGE-D1 KO }(1,60)}=2.38, p>0.1 ; F_{\text {sertraline }(2,60)}=0.07$, 
A
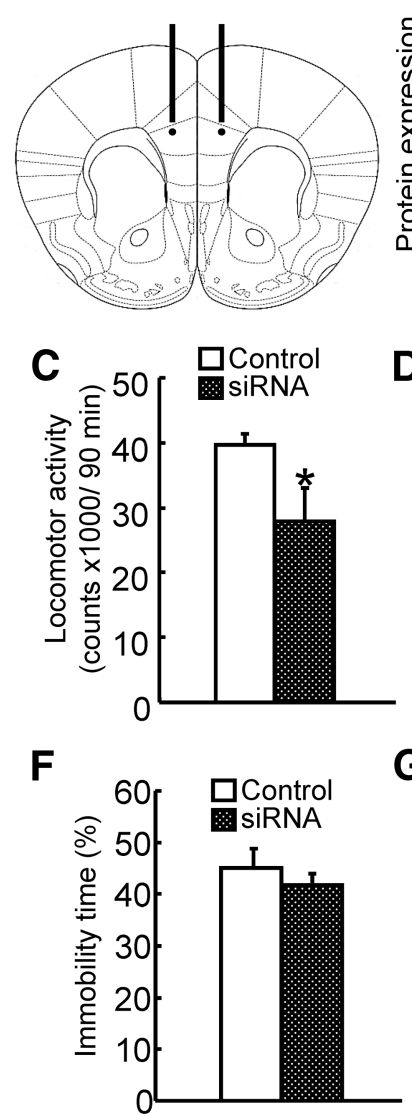
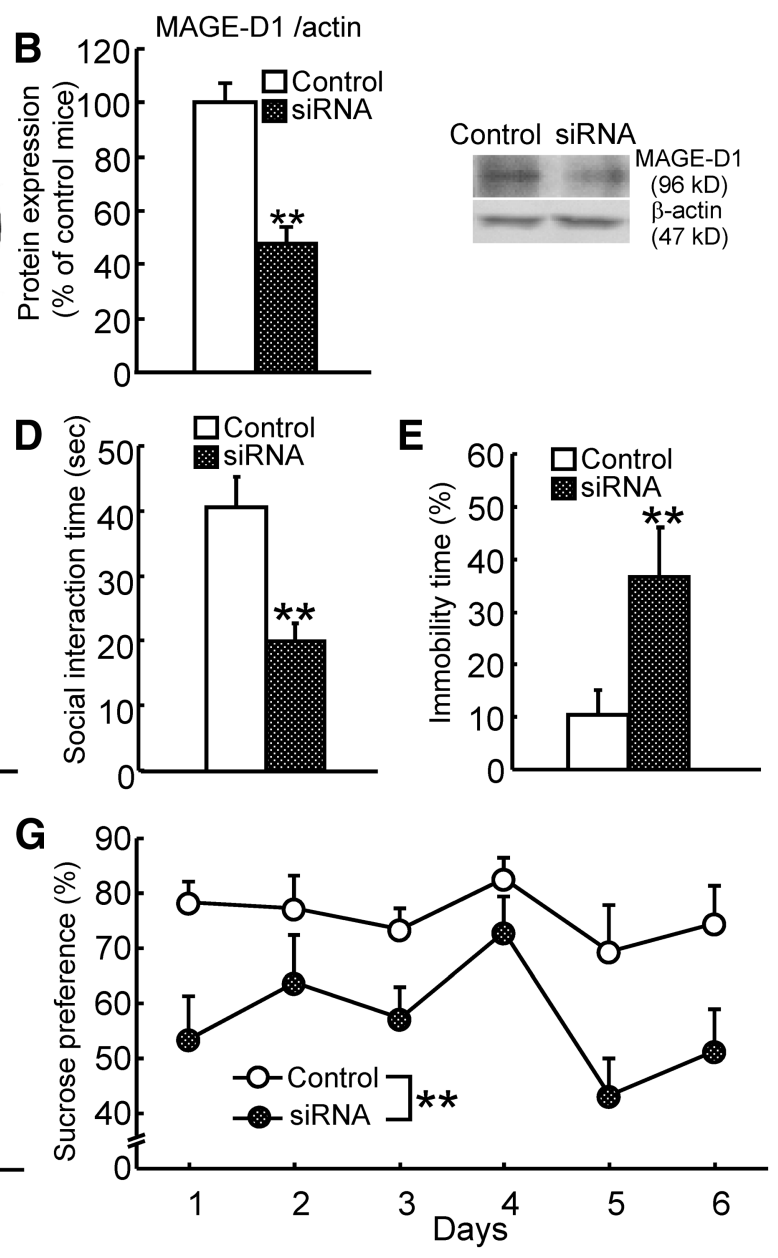

Figure 7. Depression-like behavior by MAGE-D1 knockdown caused by siRNA in the prefrontal cortex. A, A schematic representation of prefrontal cortex sections adopted from Paxinos and Franklin (2004). Bars indicate the placement of the guide cannulas (6 $\mathrm{mm}$ length: $+1.5 \mathrm{~mm}$ anteroposterior; $\pm 0.5 \mathrm{~mm}$ mediolateral from bregma; $-2.0 \mathrm{~mm}$ dorsoventral from the skull). Circles indicate the approximate site of siRNA infusion by infusion cannulas ( $6.2 \mathrm{~mm}$ length). $\boldsymbol{B}$, Protein levels of MAGE-D1 in the prefrontal cortex: protein extracts from the prefrontal cortex of MAGE-D1 siRNA-infused mice were examined by Western blotting $14 \mathrm{~d}$ after the infusion of siRNA (after behavioral tests). C, Locomotor activity of MAGE-D1 siRNA-infused mice in a novel environment. $\boldsymbol{D}$, Social interaction of MAGE-D1 siRNA-infused mice and an unfamiliar mouse in a social interaction test. $E$, $F$, Motivation of MAGE-D1 siRNA-infused mice in a tail suspension test $(\boldsymbol{E})$ and a forced swimming test $(\boldsymbol{F})$. $\boldsymbol{G}$, Natural reward of MAGE-D1 siRNA-infused mice in a sucrose preference test: each column represents the mean $\pm \operatorname{SEM}(n=10-11) .{ }^{*} p<0.05,{ }^{* *} p<0.01$ versus control siRNA-infused mice. Control, Control siRNA-infused mice; siRNA, MAGE-D1 siRNA-infused mice.

$p>0.1 ; F_{\text {MAGE-D1 KO } \times \text { sertraline }(2,60)}=3.51, p<0.05$; imipramine, two-way ANOVA, $F_{\text {MAGE-D1 KO }(1,44)}=9.87, p<0.01 ; F_{\text {imip }^{-}}$ ramine $(2,44)=3.03, p>0.05 ; F_{\text {MAGE-D1 KO } \times \text { imipramine }(2,44)}=$ $3.57, p<0.05)$ and exploratory behavior in a novel environment (Fig. 9C: sertraline, two-way ANOVA, $F_{\text {MAGE-D1 ко }(1,60)}=51.63$, $p<0.01 ; F_{\text {sertraline }(2,60)}=10.98, p<0.01 ; F_{\text {MAGE-D1 KO } \times \text { sertraline }}$ $(2,60)=0.43, p>0.1$; imipramine, two-way ANOVA, $F_{\mathrm{MAGE}}$ D1 KO $(1,44)=23.28, p<0.01 ; F_{\text {imipramine }(2,44)}=1.13, p>$ $0.1 ; F_{\text {MAGE-D1 }}$ KO $\times$ imipramine $\left.(2,44)=2.28, p>0.1\right)$ in the MAGE-D1 KO mice. These data suggest that depression-like behavior in the MAGE-D1 KO mice was responsive to acute administration with antidepressants that selectively inhibit SERT, such as sertraline, rather than with those that do not, such as imipramine.

Antidepressants acutely increase monoamine levels, but the necessity of chronic treatment has led to the hypothesis that long-term adaptations are required for the therapeutic actions of antidepressants (Duman et al., 1994). To investigate the effect of chronic antidepressant treatment on the depression-like behavior in MAGE-D1 KO mice, the mice were administered ser- traline $(10 \mathrm{mg} / \mathrm{kg})$ and imipramine $(20 \mathrm{mg} /$ $\mathrm{kg}$ ) chronically for $28 \mathrm{~d}$, and behavioral tests were performed $24 \mathrm{~h}$ after the last treatment. Sertraline and imipramine were found to decrease immobility in the MAGE-D1 KO mice in a forced swimming test (Fig. 10A: sertraline, two-way ANOVA, $F_{\text {MAGE-D1 KO }(1,29)}=$ $6.05, p<0.01 ; F_{\text {sertraline }(1,29)}=7.81$, $p<0.01 ; F_{\text {MAGE-D1 KO } \times \text { sertraline }(1,29)}=$ 2.53, $p>0.1$; imipramine, two-way ANOVA, $F_{\text {MAGE-D1 KO }(1,31)}=4.31, p<0.05$; $F_{\text {imipramine }(1,31)}=4.66, p<0.05 ; F_{\text {MAGE-D1 KO } \times}$ $\underset{\text { imipramine }(1,31)}{(1,31)}=4.14, p>0.05)$ and increase social interaction (Fig. 10B: sertraline, two-way ANOVA, $F_{\text {MAGE-D1 KO }(1,29)}=2.18, p>0.1$; $F_{\text {sertraline }(1,29)}=0.37, p>0.1 ; F_{\text {MAGE-D1 KO } \times}$ $\stackrel{ }{=} 18.92, p<0.01$; imipramine, two-way ANOVA, $F_{\text {MAGE-D1 ко }(1,31)}=$ $11.24, p<0.01 ; F_{\text {imipramine }(1,31)}=3.06$, $p>0.05 ; F_{\text {MAGE-D1 KO } \times \text { imipramine }(1,31)}=$ $16.12, p<0.01$ ) but not exploratory behavior in a novel environment (Fig. 10C; sertraline, two-way ANOVA, $F_{\text {MAGE-D1 KO }(1,29)}=$ 93.54, $p<0.01 ; F_{\text {sertraline }(1,29)}=0.75, p>$ $0.1 ; F_{\text {MAGE-D1 KO } \times \text { sertraline }(1,29)}=7.48$, $p<0.05$; imipramine, two-way ANOVA, $F_{\text {MAGE-DI KO }(131)}=96.61, p<0.01$; $F_{\text {imipramine }(1,31)}=0.49, p>0.1 ; F_{\text {MAGE-D1 }}$ KO $\times$ imipramine $(1,31)=5.10, p<0.05)$ in the MAGE-D1 KO mice. Although a decrease in exploratory behavior in MAGE-D1 KO mice was not reversed by chronic antidepressant administration, depression-like behavior was responsive to chronic antidepressant administration.

\section{Alternation of serotonergic \\ nervous system}

The difference in the acute effects of sertraline and imipramine on depression-like behavior in MAGE-D1 KO mice might be attributed to selective inhibition of serotonin reuptake. Serotonergic dysfunction is linked to hypolocomotion (Bidziński et al., 1998) and social activity (Bull et al., 2004). To study the neurochemical basis of depression-like behavior in MAGE-D1 KO mice, the amounts of serotonin and its metabolite in the six regions of brain (prefrontal cortex, hippocampus, amygdala, hypothalamus, striatum, and nucleus accumbens) of MAGE-D1 KO mice were measured (Fig. 11 A$F)$. Serotonin content in the prefrontal cortex of MAGE-D1 KO mice was found to be significantly lower than that in the prefrontal cortex of wild-type mice but was found to be higher in the hippocampus of MAGE-D1 KO mice than in those of wild-type mice (Fig. $11 A$ : Student's $t$ test, $t_{(18)}=2.13, p<0.05$; Fig. $11 B$ : Student's $t$ test, $\left.t_{(18)}=-3.17, p<0.01\right)$. The level of the metabolite of serotonin (5-HIAA) was significantly reduced in the amygdala (Fig. $11 C$ : Student's $t$ test, $t_{(18)}=3.04, p<0.01$ ). Serotonin turnover, assessed by the ratio 5-HIAA/serotonin, was significantly low in the hippocampus and amygdala (Fig. $11 \mathrm{~B}$ : Student's $t$ test, $t_{(18)}=2.43, p<0.05$; Fig. 9 C: Student's $t$ test, $t_{(18)}=$ $3.63, p<0.01)$. 
To further investigate serotonergic function in MAGE-D1 KO mice, changes in the release of serotonin in the prefrontal cortex and hippocampus were investigated by microdialysis (Fig. 11G,H). There was found to be no difference in the basal levels of serotonin in the prefrontal cortex and hippocampus between wildtype and MAGE-D1 KO mice (prefrontal cortex: wild-type, $0.55 \pm 0.13 \mathrm{pmol} / 10$ $\mu \mathrm{l} / 10 \mathrm{~min}$; MAGE-D1 KO, $0.46 \pm 0.21$ $\mathrm{pmol} / 10 \mu \mathrm{l} / 10 \mathrm{~min}$; hippocampus: wildtype, $0.55 \pm 0.13 \mathrm{pmol} / 10 \mu \mathrm{l} / 10 \mathrm{~min}$; MAGE-D1 KO, $0.46 \pm 0.21 \mathrm{pmol} / 10$ $\mu \mathrm{l} / 10 \mathrm{~min})$. The amount of extracellular serotonin was increased by stimulation with high potassium $(50 \mathrm{~mm})$ in the prefrontal cortex and hippocampus in both genotypes of mice, but the increase was significantly lower in the MAGE-D1 KO mice (Fig. 11G: repeated-measures ANOVA, prefrontal cortex, $F_{\text {MAGE-D1 KO (1,21) }}=25.64, p<0.01$; $F_{\text {time }(3,21)}=2.25, p>0.1 ; F_{\text {MAGE-D1 KO } \times}$ $\stackrel{\text { time }(3,21)}{=}=0.56, p>0.1$; Fig. $11 \mathrm{H}$ : repeatedmeasures ANOVA, hippocampus, $F_{\text {MAGE-D1 KO }(1,21)}=10.54, p<0.05$; $F_{\text {time }(3,21)}=13.48, p<0.01 ; F_{\text {MAGE-D1 KO } \times}$ $\left.{ }^{\text {time }}{ }^{(3,21)}=4.40, p<0.05\right)$. These results indicate that a deficiency of MAGE-D1 results in hyposerotonergic function in the prefrontal cortex and hippocampus.

\section{Increase of SERT protein expression} and decrease in its ubiquitylation in the prefrontal cortex

It is possible that a deficiency in MAGED1 affects the expression of serotonergic nervous system-related proteins, such as synthetases, degradation enzymes, and transporters. To test this possibility, the expression of TPH2, MAO-A, and SERT was analyzed by Western blotting. There was found to be no significant difference in TPH2 and MAO-A protein levels in the prefrontal cortex between wild-type and MAGE-D1 KO mice (Fig. 12A: Student's $t$ test, TPH2, $t_{(22)}=1.19, p>0.1$; MAO-A, $\left.t_{(22)}=1.08, p>0.1\right)$. However, SERT expression level in the prefrontal cortex was significantly higher in the MAGE-D1 KO mice (Fig. 12A: $t_{(22)}=-5.80, p<0.01$ ). An increase in SERT expression was also observed by infusion of MAGE-D1 siRNA into the prefrontal cortex (Fig. 12B: $t_{(9)}=-2.30, p<0.01$ ). The immunohistochemistry with SERT antibody also showed strong immunoreactivity in the prefrontal cortex of MAGE-D1 KO mice (Fig. 12C). At the mRNA levels of SERT, there was no significant difference in the prefrontal cortex between the wild-type and MAGE-D1 KO mice (Fig. 12D: Student's $t$ test, $t_{(21)}=-0.78, p>0.1$ ).

Ubiquitylation is often a signal for degradation by the proteasome (Hershko and Ciechanover, 1982). To determine whether MAGE-D1 regulates the SERT protein level by ubiquitin-dependent proteolysis, we measured ubiquitylated SERT levels by Western blotting with SERT antibody in the precipitated ubiquitylated protein. Ubiquitylated SERT expression level in the prefrontal cortex was found to be significantly lower in the prefrontal cortex of MAGE-D1 KO mice (Fig. 12E: Student's $t$ test, $t_{(22)}=3.58, p<0.01$ ). These data
A

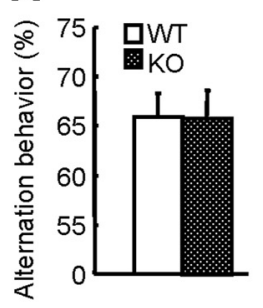

B

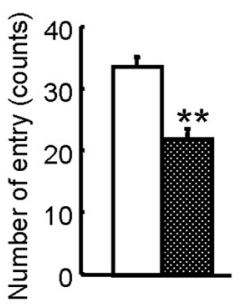

E
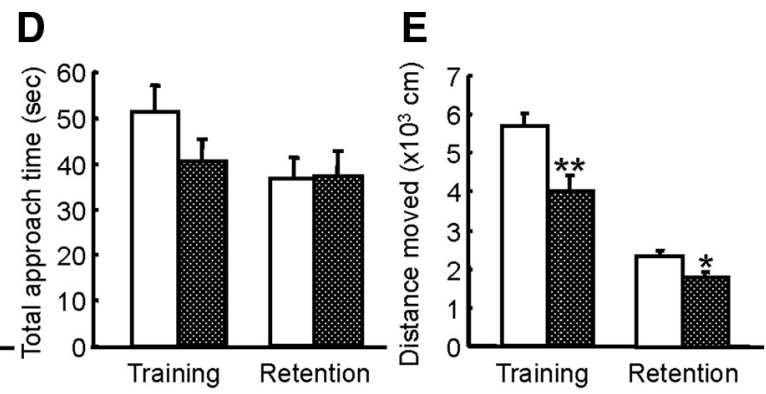

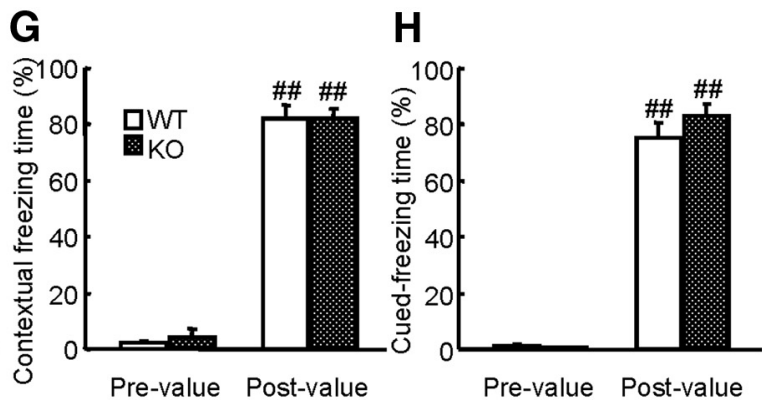

Figure 8. Normal cognitive functions in the MAGE-D1 K0 mice. $\boldsymbol{A}, \boldsymbol{B}$, Short-term memory in a Y-maze test of the MAGE-D1 K0 mice. Alternation behavior $(\boldsymbol{A})$ and total arm entries $(\boldsymbol{B})$ were measured during an 8 min session. $\boldsymbol{C}-\boldsymbol{E}$, Objective recognition memory of the MAGE-D1 $\mathrm{KO}$ mice in a novel-object recognition test. The retention session was performed $24 \mathrm{~h}$ after the training cued $(\boldsymbol{H})$ freezing time in the postconditioning were measured $24 \mathrm{~h}$ after the preconditioning. Each column represents the mean $\pm \operatorname{SEM}(n=10) .{ }^{*} p<0.05,{ }^{* *} p<0.01$ versus wild-type mice. ${ }^{\#} p<0.05,{ }^{\# \#} p<0.01$ versus corresponding training $(\boldsymbol{C})$, nontrained mice $(\boldsymbol{F})$, and prevalue $(\boldsymbol{G}, \boldsymbol{H})$. WT, Wild-type mice.

suggest that the hyposerotonergic response in MAGE-D1 KO mice might be attributable to an increased level of SERT expression resulting from a decrease in ubiquitin-dependent proteolysis.

\section{MAGE-D1 decreases SERT expression and serotonin uptake activity}

MAGE-D1 deficiency was found to decrease serotonergic function by increasing the SERT expression level in the mouse brain. To investigate the role of MAGE-D1 in the expression of SERT, we investigated whether MAGE-D1 overexpression decreases the SERT expression and serotonin uptake activity by using CHO-rSERT cells stably expressing SERT. First, we investigated the protein level of SERT in CHO-rSERT cells with MAGE-D1 overexpression by Western blotting. The protein level of SERT was reduced by transfection of MAGE-D1 (Fig. $13 A$ : Student's $t$ test, $\left.t_{(8)}=2.41, p<0.05\right)$. Next, we investigated the activity of SERT in CHO-rSERT cells with MAGE-D1 overexpression. Transfection of MAGE-D1 resulted in a significantly lower level of $\left[{ }^{3} \mathrm{H}\right]$ serotonin uptake in these cells than was found in control CHO-rSERT cells mock transfected with pcDNA3 vector, and a decrease in SERT expression was also observed (Fig. 13B: two-way ANOVA, 


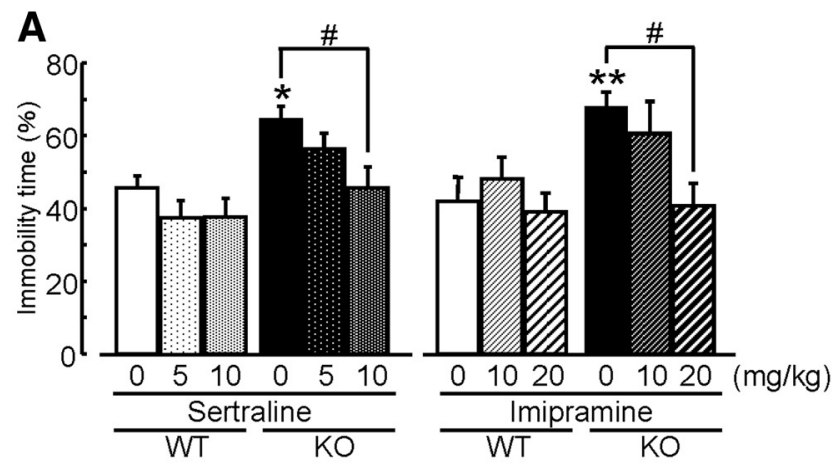

B
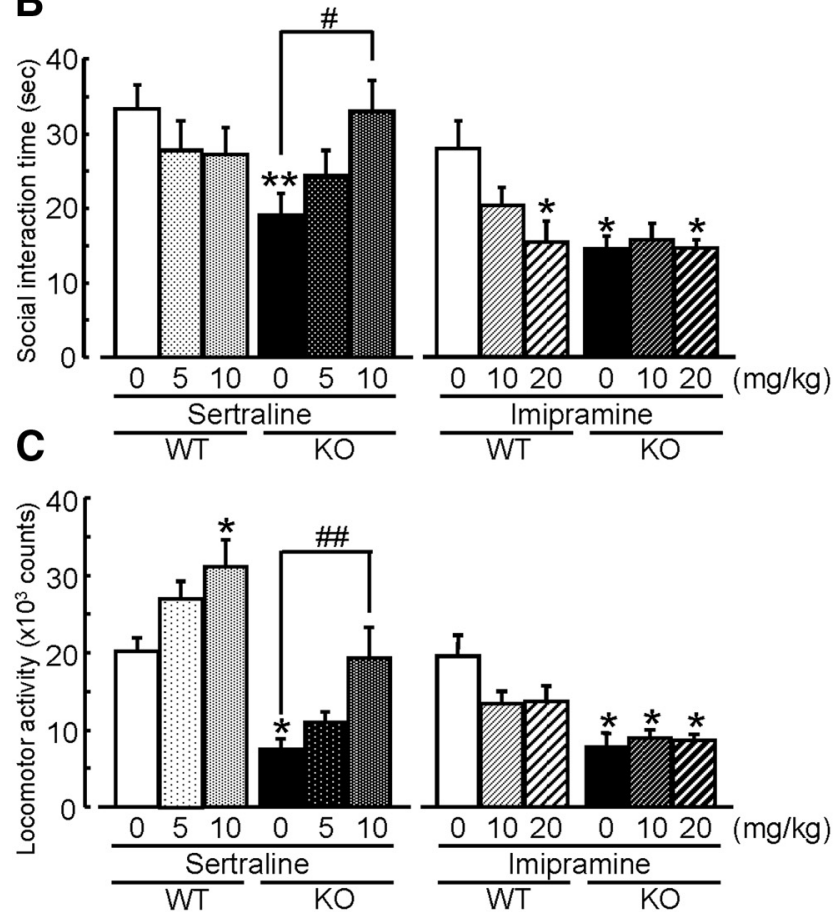

Figure 9. Acute administration of antidepressants attenuates depression-like behavior in the MAGE-D1 KO mice. $\boldsymbol{A}-\boldsymbol{C}$, Effects of acute sertraline and imipramine treatment on depression-like behavior observed in the MAGE-D1 KO mice. Sertraline $(5$ and $10 \mathrm{mg} / \mathrm{kg}$, i.p.) and imipramine ( $10 \mathrm{and} 20 \mathrm{mg} / \mathrm{kg}$, i.p.) were administered to the MAGE-D1 KO mice 30 min before a forced swimming test $(\boldsymbol{A})$, a social interaction test $(\boldsymbol{B})$, and a locomotor activity test $(\boldsymbol{C})$. Each column represents the mean $\pm \operatorname{SEM}(n=6-13) .{ }^{*} p<0.05,{ }^{* *} p<$ 0.01 versus vehicle-treated wild-type mice. ${ }^{\#} p<0.05,{ }^{\# \#} p<0.01$ versus vehicle-treated MAGE-D1 K0 mice. WT, Wild-type mice.

$F_{\text {MAGE-D1 }(1,36)}=16.94, p<0.01 ; F_{\text {nonlabeled serotonin }(5,36)}=$ $405.88, p<0.01 ; F_{\text {MAGE-D } 1 \times \text { nonlabeled serotonin }(5,36)}=2.14, p>$ $0.05)$. Kinetic analysis of $\left[{ }^{3} \mathrm{H}\right]$ serotonin uptake showed that $V_{\max }$ was decreased when MAGE-D1 was transfected, without any changes in the $K_{\mathrm{m}}$ of SERT (Fig. $13 B$ : Student's $t$ test, $V_{\max }$, $\left.t_{(6)}=2.45, p<0.05 ; K_{\mathrm{m}}, t_{(6)}=0.35, p>0.1\right)$.

\section{MAGE-D1 interacts with SERT}

It has been suggested that MAGE-D1 plays the role of an adaptor molecule in the ubiquitin-dependent degradation pathway (Sasaki et al., 2002). To determine how MAGE-D1 decreases SERT expression by ubiquitylation, we first examined whether MAGE-D1 binds to SERT. We transfected CHO-rSERT cells with epitope (HA)tagged MAGE-D1, and their binding was examined by anti-SERT immunoprecipitation followed by anti-HA immunoblotting. Immunoprecipitation of SERT was accompanied by coimmunoprecipitation of HA-tagged MAGE-D1 and vice versa (Fig. 13C),

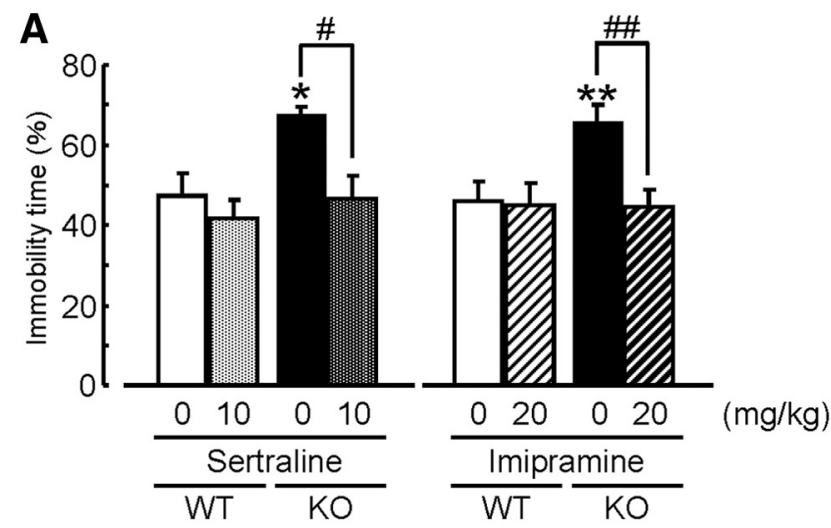

B
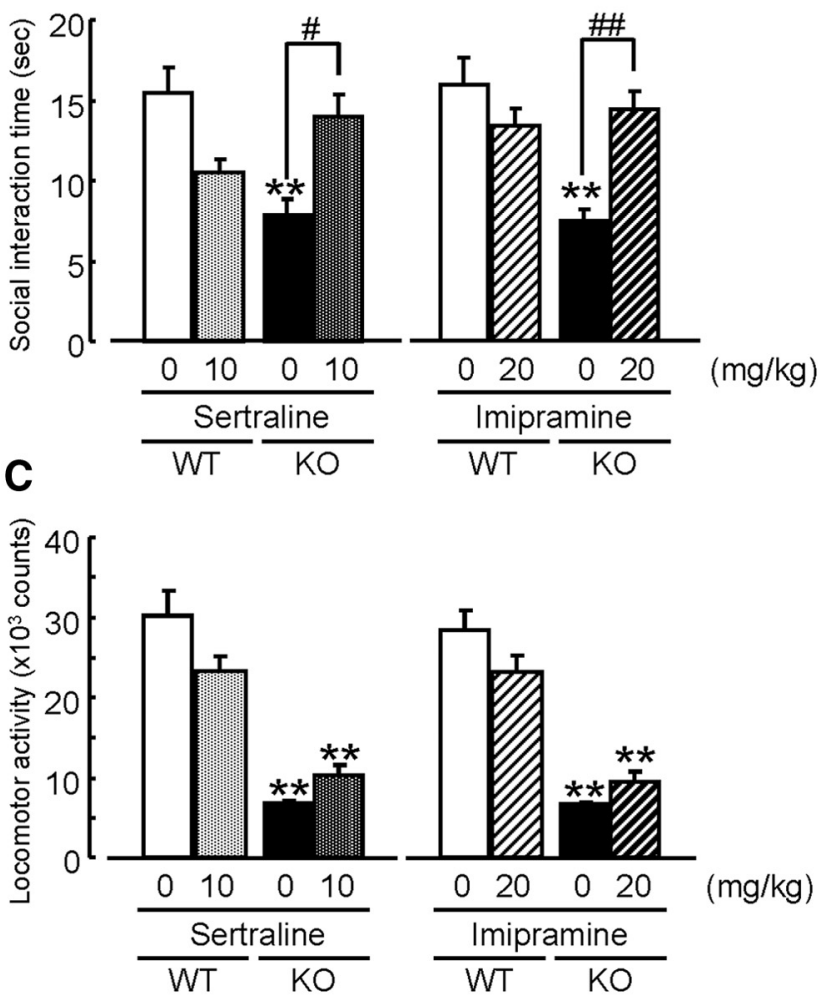

Figure 10. Chronic administration of antidepressants attenuates depression-like behavior in the MAGE-D1 K0 mice. $\boldsymbol{A}-\boldsymbol{C}$, Effects of chronic sertraline and imipramine administration on depression-like behavior observed in MAGE-D1 K0 mice. Sertraline (10 mg/kg, i.p.) and imipramine ( $20 \mathrm{mg} / \mathrm{kg}$, i.p.) were chronically administered to the MAGE-D1 K0 mice for $28 \mathrm{~d}$. A forced swimming test $(\boldsymbol{A})$, social interaction test $(\boldsymbol{B})$, and locomoto activity test $(\boldsymbol{C})$ were performed $24 \mathrm{~h}$ after the last treatment. Each column represents the mean \pm SEM $(n=8-9) .{ }^{*} p<0.05,{ }^{* *} p<0.01$ versus vehicle-treated wild-type mice. ${ }^{\#} p<0.05,{ }^{\# \#} p<0.01$ versus vehicle-treated MAGE-D1 K0 mice. WT, Wild-type mice.

suggesting an interaction of SERT with MAGE-D1. To understand the biological relevance of the observed molecular associations of MAGE-D1 with SERT, we examined the subcellular distribution of MAGE-D1 and of SERT proteins in transfected CHO-rSERT cells by immunofluorescence. When HA-tagged MAGE-D1 was expressed in CHO-rSERT cells, HA-MAGE-D1 was detected in the cytoplasm, plasma membrane, and endoplasmic reticulum in colocalization with SERT (Fig. 13D). It was consistent with immunoprecipitation analyses showing that MAGE-D1 binds with SERT (Fig. 13C). To investigate whether MAGE-D1 and SERT interact not only when ectopically expressed in transfected CHO-rSERT cells but also in more physiological settings, we then analyzed the SERT- 
MAGE-D1 interaction in the mouse brain. Immunoprecipitation of SERT from mouse brain homogenate was found to coimmunoprecipitate MAGE-D1 (Fig. $13 E)$. In addition, confocal analysis was performed on brain sections stained with anti-MAGE-D1 and anti-SERT. Immunoreactivity to MAGE-D1 colocalized with that to SERT in some axons of the prefrontal cortex (Fig. 13F), suggesting colocalization of MAGE-D1 and SERT in the same cell. Thus, these results show that MAGE-D1 interacts with SERT both in vitro and in vivo.

MAGE-D1 consists of three domains, $\mathrm{N}$-terminal domain, internal unique repetitive domain, and NHD; the homology of the latter is shared in the MAGE protein family (Fig. 13G). We examined several deletion mutants of MAGE-D1 for their association with SERT, as shown in Figure 13G. We found that SERT coimmunoprecipitated with HA-tagged MAGE-D1 and MAGED1-NHD, but not with MAGE-D1-N or MAGE-D1-W (Fig. 13H). This indicates that the NHD of MAGE-D1 is responsible for its binding with SERT.

\section{MAGE-D1 modulates SERT}

degradation by ubiquitylation

We investigated the involvement of the proteasome in SERT degradation by examining SERT levels in cells exposed to proteasome inhibitor. CHO-rSERT cells were exposed to MG132 (carbobenzoxyL-leucyl-L-leucyl-L-leucinal), which inhibits the activity of the $26 \mathrm{~S}$ proteasome in cultured cells, and SERT levels were determined by Western blotting (Fig. 14A). In the control group, although the levels of SERT $(76 \mathrm{kDa})$ were unchanged (Fig. $14 B$ : two-way ANOVA, $F_{\text {MG132 }(3,28)}=$ $0.92, p>0.1 ; F_{\text {MAGE-D1 }(1,28)}=1.15, p>$ $\left.0.1 ; F_{\text {MAGE-D1 }}(3,28)=2.15, p>0.1\right)$, MG132 dose dependently increased the amount of high-molecular-weight immunoreactive smears $(\sim 100 \mathrm{kDa})$ recognized by SERT antibody (Fig. 14C: two-way ANOVA, $F_{\text {MG132 }(3,28)}=28.43$, $p<0.01 ; F_{\text {MAGE-D1 }(1,28)}=23.22, p<$ $\left.0.01 ; F_{\text {MAGE-D1 }(3,28)}=3.89, p<0.05\right)$.

To investigate the effect of MAGE-D1 overexpression on the MG132-induced SERT-immunoreactive smears, we exposed MG132 to MAGE-D1-transfected CHO-rSERT cells. Although it was not statistically different, the reduction in SERT $(76 \mathrm{kDa})$ in the presence of MAGE-D1 was reversed by administration of MG132 (Fig. 14B). In addition, transfected MAGE-D1 significantly intensified MG132-induced highmolecular-weight SERT antibody-immunoreactive smears $(\sim 100 \mathrm{kDa})$ (Fig. 14C).

We then identified high-molecular-weight SERT antibody-immunoreactive smears $(\sim 100 \mathrm{kDa})$ in MAGE-D1transfected CHO-rSERT cells. The lysates from MG132-exposed control and MAGE-D1-transfected CHO-rSERT cells were immu-
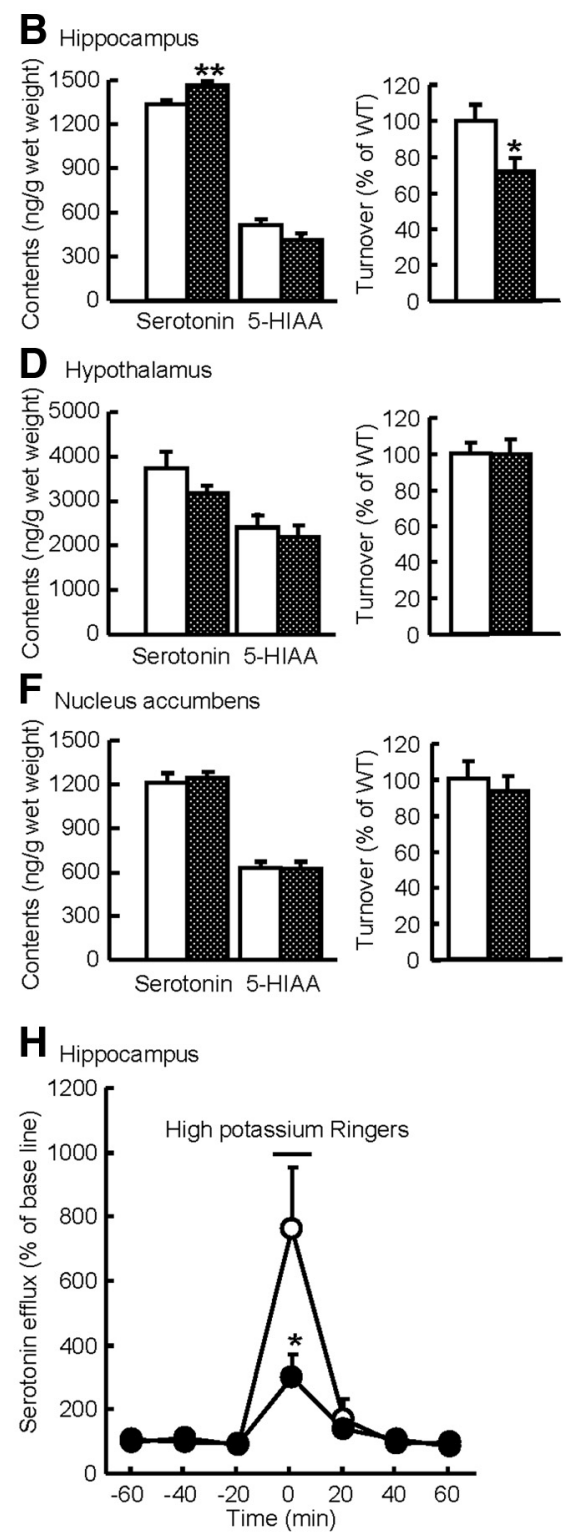

Figure 11. Alternation of the serotonergic neuronal system in the MAGE-D1 K0 mice. $\boldsymbol{A}-\boldsymbol{F}$, Alternation of serotonin and its metabolite amounts and turnover in the brain regions of MAGE-D1 KO mice. The amounts of serotonin and its metabolite

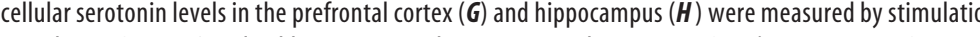
of high potassium in the MAGE-D1 K0 and wild-type mice. Values represent the mean \pm SEM $(\boldsymbol{A}-\boldsymbol{F}, n=10 ; \boldsymbol{G}, \boldsymbol{H}, n=$ $4-5) .{ }^{*} p<0.01,{ }^{* *} p<0.05$ versus wild-type mice. WT, Wild-type mice.

noprecipitated with anti-ubiquitin, separated by SDS-PAGE, and immunoblotted with SERT antibody. In the absence of exogenous MAGE-D1, smears corresponding to polyubiquitylated SERT were detected. The level of these conjugates was increased by transfection of MAGE-D1 in the presence of MG132 (Fig. 14A, middle). Furthermore, exogenous MAGE-D1 was also increased by MG132 (Fig. 14D: two-way ANOVA, $F_{\text {MG132 }(3,28)}=108.41, p<0.01 ; F_{\text {MAGE-D1 }(1,28)}=$ $\left.14.43, p<0.01 ; F_{\text {MAGE-D1 }(3,28)}=11.55, p<0.01\right)$, suggesting that MAGE-D1 also degraded through a proteasome pathway. These results indicate that SERT is ubiquitylated and degraded by proteasome and that MAGE-D1 controls this ubiquitylation process. 
A
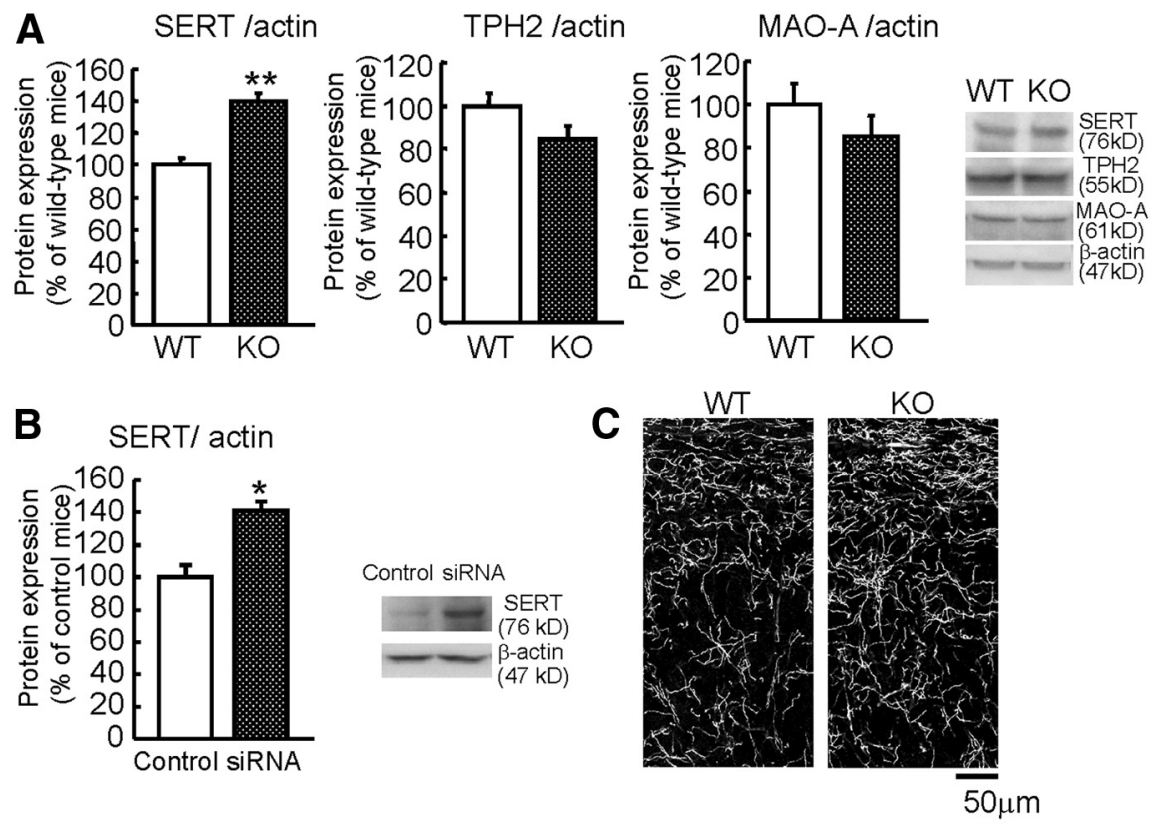
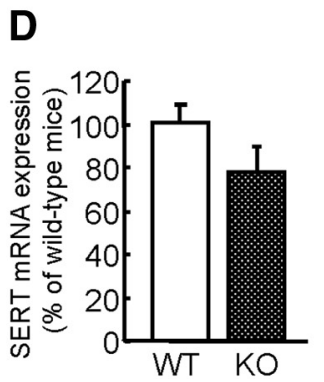

E

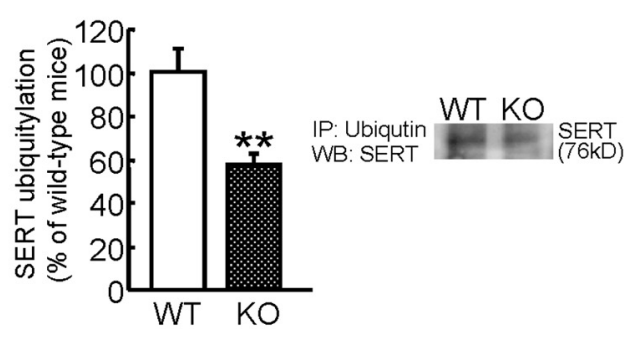

Figure 12. Increase in SERT protein expression and decrease in its ubiquitylation in the prefrontal cortex of MAGE-D1 KO mice. $A$, Increased SERT protein expression in the frontal cortex of MAGE-D1 KO mice: the expression of SERT, TPH2, and MA0-A were analyzed by Western blotting of homogenates from the prefrontal cortex of MAGE-D1 KO and wild-type mice. $B$, Increase of immunoreactivity of SERT in the prefrontal cortex of MAGE-D1 KO mice: confocal immunofluorescent images of SERT were obtained from coronal sections from the prefrontal cortex of MAGE-D1 K0 and wild-type mice. $C$, Increased SERT protein expression in the prefrontal cortex of MAGE-D1 knockdown mice caused by siRNA: SERT protein expression in the prefrontal cortex of MAGE-D1 siRNA-infused mice were examined by Western blotting. $\boldsymbol{D}$, No difference in SERT mRNA in the frontal cortex between two genotypes. $E$, Decrease in SERT protein ubiquitylation in the prefrontal cortex of MAGE-D1 KO mice: the ubiquitylation of SERT was analyzed by Western blotting with SERT antibody in the precipitated ubiquitylated protein of the prefrontal cortex of MAGE-D1 K0 and wild-type mice. Values represent the mean \pm SEM $(n=12) .{ }^{* *} p<$ 0.01 versus wild-type mice. IP, Immunoprecipitation; WB, Western blot; WT, Wild-type mice.

\section{Discussion}

Depression-like behavior in the MAGE-D1 KO mice

In this study, we analyzed mice with an MAGE-D1 deficiency to define the role of MAGE-D1 in emotional and cognitive functions. One result of the study was that MAGE-D1 KO mice demonstrated a decrease in activity in both their home cages and a novel apparatus. It has been established that a decrease in locomotor activity in the home cage or during a treadmill/running wheel activity is model of fatigue (or loss of energy) as a symptom of depression in mice (Cryan and Holmes, 2005). Psychomotor retardation, another feature of depression, has been mimicked in pharmacological and stressinduced animal models of depression by reduced levels of activity (Willner, 1991; Overstreet, 1993). It is also noteworthy that a decrease in exploratory behavior in a novel apparatus is also observed in some genetical depression animal models (Ansorge et al., 2004; Fukui et al., 2007).

MAGE-D1 KO mice in this study also demonstrated a decrease in social interaction. Social withdrawal is modeled in depression as di- minished interest (Cryan and Holmes, 2005). In rodents, the social interaction test is used for assessing anxiety-like behavior (File, 1980). In our test, we deliberately used low-light and habituated conditions that are not expected to generate anxiety, to rule out the possibility that the rodents' decreased social interaction may have resulted in part from increased levels of anxiety.

Another of our findings was that MAGE-D1 KO mice revealed an increase in immobility time during the forced swimming test. Immobility during a forced swimming test has been called an example of behavioral despair and appears to be selectively sensitive to antidepressants, suggesting that this behavioral change can be regarded as depression (Porsolt et al., 1977a). This test has already been successfully used to demonstrate the role of genes in the pathogenesis of depression (Boyle et al., 2005; Fukui et al., 2007). It should be emphasized that the increase in immobility in the MAGE-D1 KO mice was not caused by a decrease in locomotor activity, because the effects of antidepressants were behaviorally specific: imipramine decreased immobility time in the forced swimming test but did not reverse a decrease in exploratory behavior in a novel environment in the MAGE-D1 KO mice.

The MAGE-D1 KO mice in this study also exhibited reduced reward responsiveness in a sucrose preference test. This is a model of anhedonia, a key depressive symptom characterized by a markedly diminished degree of pleasure derived from everyday activities (Willner et al., 1987).

Finally, MAGE-D1 knockdown in the adult prefrontal cortex mimicked the depression-like behavior in the MAGE-D1 KO mice. Thus, this study can be said to have shown with good face validity that MAGE-D1 deficiency in mice leads to depression-like behavior.

\section{Pharmacological response to antidepressants in MAGE-D1 KO mice}

Predictive validity is an important criterion for evaluating the usefulness of an animal model as a screening device for new drugs. The pharmacological responses to antidepressants in the present study confirmed that the behavioral changes observed in the MAGE-D1 KO mice were related to depression.

Acute administration of sertraline and imipramine decreased immobility in MAGE-D1 mice in a forced swimming test with similar dose dependence as reported previously ( $\mathrm{Da}$ vid et al., 2001; Nakamura et al., 2006). Also, acute administration of sertraline reversed a decrease in social interaction and exploratory behavior in a novel environment in the MAGE-D1 KO mice, although imipramine did not have this effect. The difference in the acute effects of sertraline and imipramine might be attributed to selective inhibition of se- 


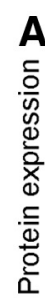
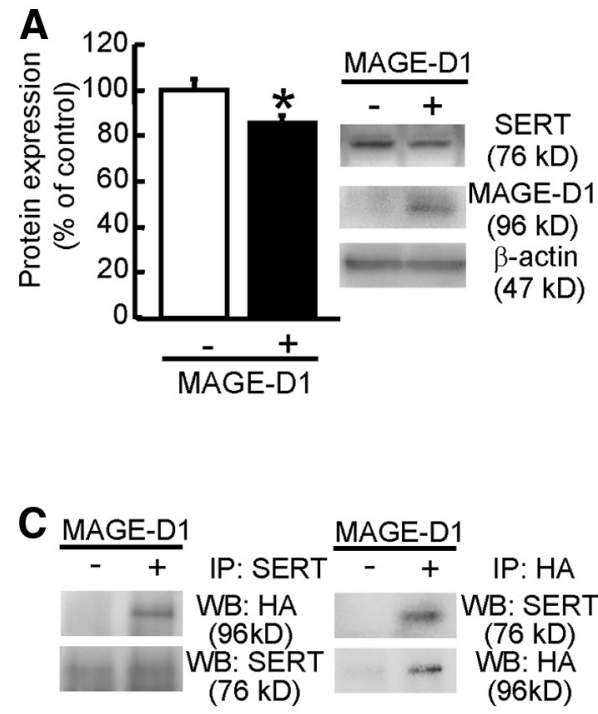

E

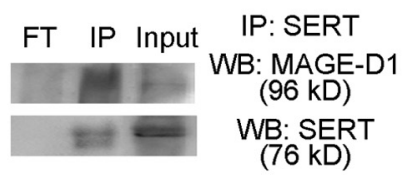

G

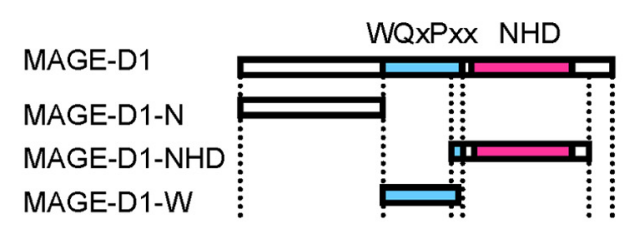

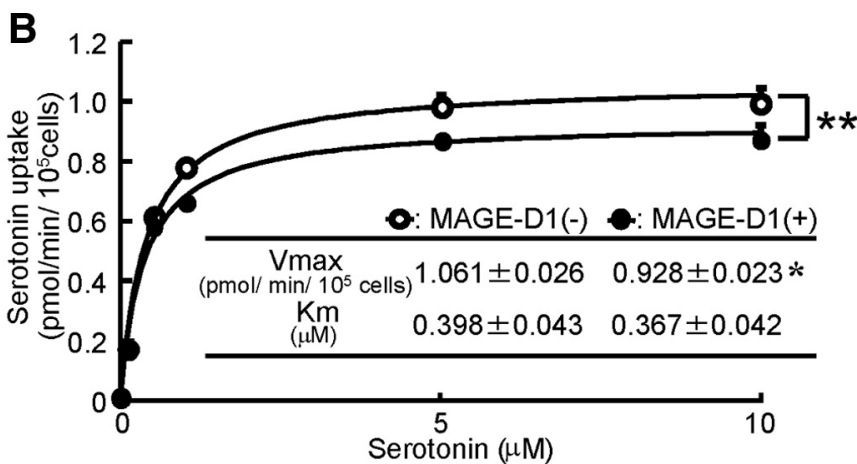
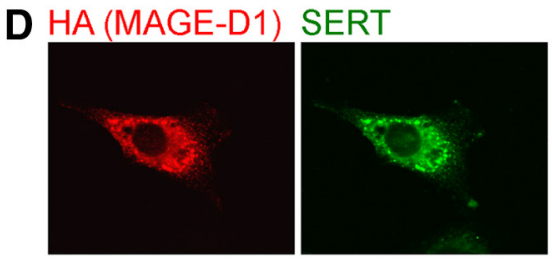

Merge

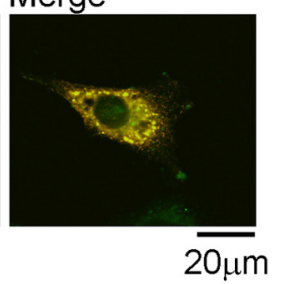

F MAGE-D1
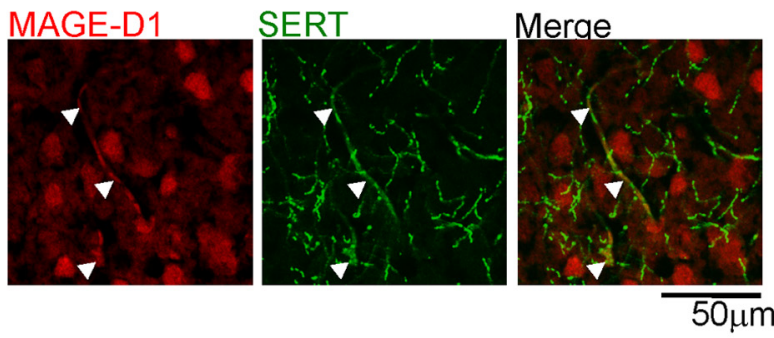

H

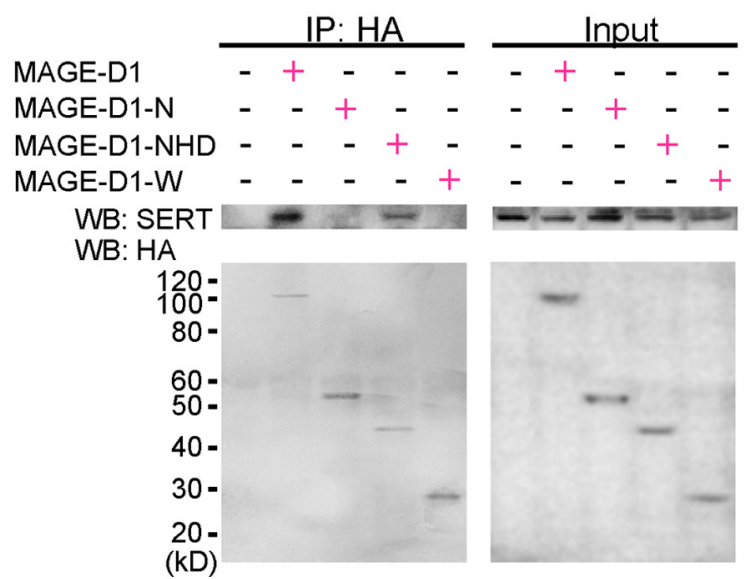

Figure 13. MAGE-D1 interacts with SERT and decreases its expression and serotonin uptake activity. $\boldsymbol{A}$, MAGE-D1 overexpression decreased SERT expression: CHO-rSERT cells were transfected with MAGE-D1, and protein expression was determined by Western blotting using anti-SERT, anti-MAGE-D1, and anti- $\beta$-actin. B, MAGE-D1 overexpression decreased SERT activity: SERT activity $\left(V_{\max }\right.$ and $\left.K_{\mathrm{m}}\right)$ in MAGE-D1-transfected CHO-rSERT was determined by saturation curves of serotonin uptake. C, MAGE-D1 interacts with SERT in MAGE-D1transfected CHO-rSERT cells: cell lysates were prepared from CHO-rSERT cells transfected with the expression vectors containing HA-tagged rat MAGE-D1 CDNA. Anti-SERT or anti-HA immunoprecipitates from the respective cell lysates were analyzed by Western blotting using anti-HA or anti-SERT. D, Subcellular colocalization of MAGE-D1 and SERT: a confocal analysis was performed on MAGE-D1-transfected CHO-rSERT cells stained with anti-HA (red) and anti-SERT (green). $E$, Physiological interactions of MAGE-D1 with SERT in mouse brain: the flow-through fraction (FT), anti-SERT immunoprecipitates from the homogenate, or homogenate from mouse frontal cortex (input) were analyzed by Western blotting using antiMAGE-D1 or anti-SERT. $\boldsymbol{F}$, Colocalization of MAGE-D1 and SERT in mouse brain: confocal analysis was performed on brain sections from mouse prefrontal cortex stained with antiMAGE-D1 (red) and anti-SERT (green). The white arrow indicates colocalization of MAGE-D1 and SERT. G, Schematic representation of the full-length and deletion mutants of MAGE-D1: the central portion of MAGE-D1 contains 25 repeats of the hexapeptide WQXPXX. The C-terminal one-third of MAGE-D1 contains an NHD. H, SERT binds to the C-terminal portion of MAGE-D1 containing the NHD: CHO-rSERT cells were transfected with expression vectors encoding the respective MAGE-D1 mutants. Immunoprecipitation with anti-HA and Western blotting with anit-SERT were performed as described in $\boldsymbol{C}$. Values represent the mean $\pm \operatorname{SEM}(\boldsymbol{A}, \boldsymbol{B}, n=4) .{ }^{*} p<0.05,{ }^{* *} p<0.01$ versus control-transfected CH0-rSERT cells. IP, Immunoprecipitates; WB, Western blotting. 


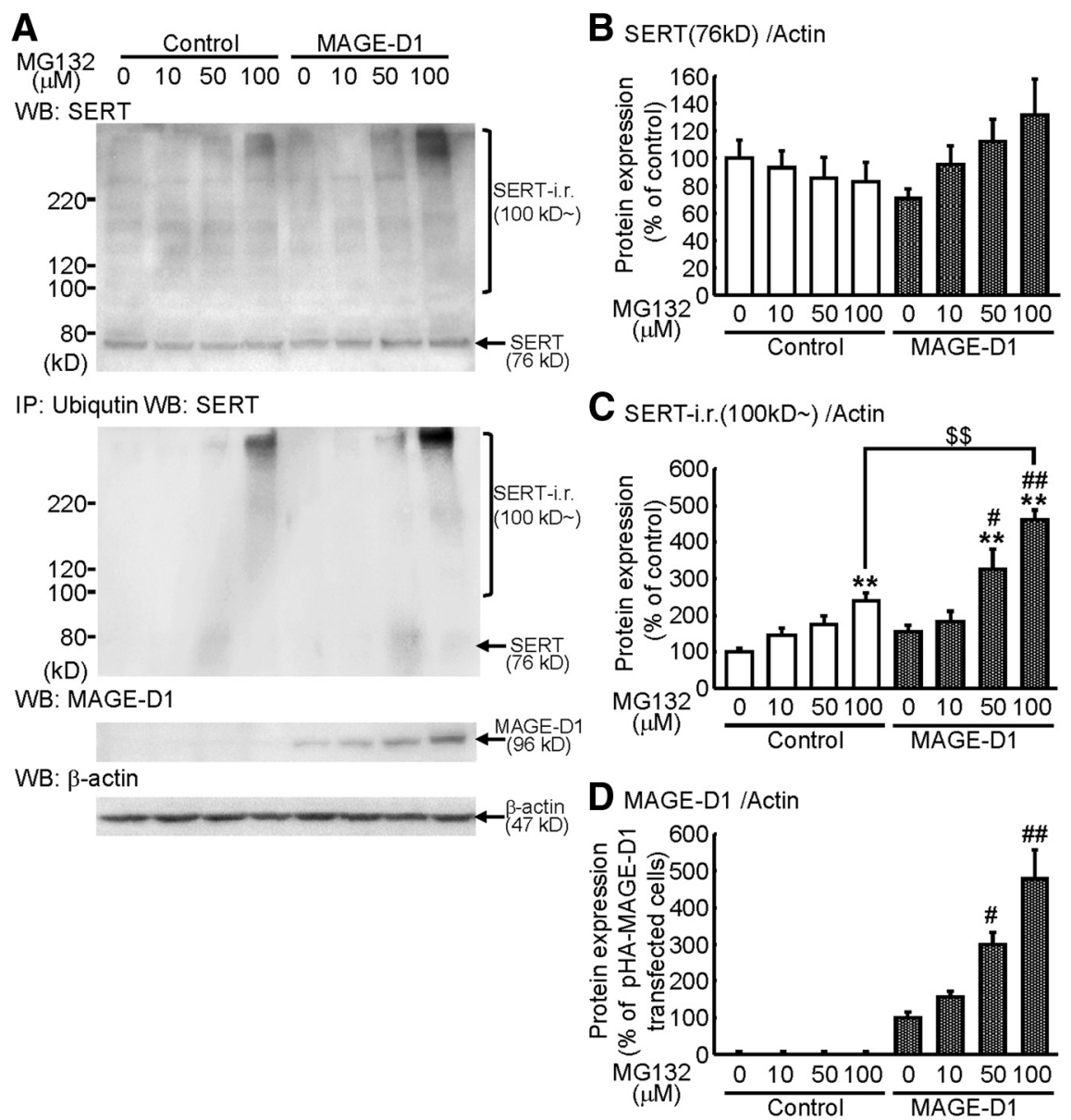

Figure 14. MAGE-D1 modulates SERT degradation by ubiquitylation. $A$, SERT as well as MAGE-D1 was degraded through a proteasome pathway and polyubiquitylation of SERT was enhanced by MAGE-D1: cell lysates were prepared from CHOrSERT cells transfected with the expression vectors containing HA-tagged rat MAGE-D1 CDNA with or without MG132 treatment. Cell lysates and anti-ubiquitin immunoprecipitates (IP) from the respective cell lysates were analyzed by Western blotting (WB) using anti-SERT or anti-MAGE-D1. $\boldsymbol{B}-\boldsymbol{D}$, Expressions of SERT (B), high-molecular-weight SERT antibody-immunoreactive smears ( $\sim 100 \mathrm{kDa})(\boldsymbol{C})$ and MAGE-D1 (D) were analyzed. Values represent the mean \pm SEM $(n=4-5) .{ }^{* *} p<0.01$ versus control-transfected/vehicle-treated CHO-rSERT cells. ${ }^{\#} p<0.05,{ }^{\# \# p} p 0.01$ versus MAGE-D1-transfected/vehicle-treated CH0-rSERT cells. ${ }^{\$ \$} p<0.01$ versus MG132 (100 $\left.\mu \mathrm{m}\right)$-treated CH0-rSERT cells.

rotonin reuptake ( $K_{\mathrm{i}}$ for SERT: sertraline, $4.2 \pm 0.7$; imipramine, $61 \pm 4 \mathrm{~nm}$ ) (Richelson, 2001; Tavoulari et al., 2009).

Chronic sertraline and imipramine administration, meanwhile, decreased immobility time in the forced swimming test and reversed a decrease in social behavior but not a decrease in exploratory behavior in a novel environment in the MAGE-D1 KO mice. However, chronic sertraline and imipramine administration did not affect an increase of SERT expression in the frontal cortex of the MAGE-D1 KO mice (data not shown). Although chronic administration of antidepressants attenuated part of the depression-like behavior in the MAGE-D1 KO mice, the effects were not associated with modulation of SERT metabolism. Although additional experiments are needed, these pharmacological responses during behavioral tasks suggest that MAGE-D1 KO mice have the potential to be a model with predictive validity for assessments of new antidepressants.

\section{Serotonergic hypofunction in MAGE-D1 KO mice}

Insufficiency of serotonergic CNSs may play a key role in the pathophysiology of depression (Stockmeier, 2003). Depressed patients ex- hibit reduced cerebrospinal fluid levels of 5-HIAA (Owens and Nemeroff, 1994) and tryptophan depletion-induced transient relapse during successful treatment with selective serotonin reuptake inhibitors (Owens and Nemeroff, 1994). SERT binding, meanwhile, is elevated in some brain areas, including the frontal cortex of major depressive disorder patients (Reivich et al., 2004; Cannon et al., 2007). In the present study, MAGE-D1 KO mice exhibited decrease in amounts of serotonin or 5-HIAA and/or decrease in turnover (ratio of 5-HIAA/serotonin) and lower extracellular serotonin levels induced by high potassium in the prefrontal cortex and hippocampus. In addition, there was an increase in SERT protein level in the prefrontal cortex of the MAGE-D1 KO mice. These data suggest that depression-like behavior in the MAGE-D1 KO mice was associated with serotonergic hypofunction. Thus, the deficiency of MAGE-D1 induced not only behavioral but also neurological phenotypes of depression, suggesting that MAGE-D1 $\mathrm{KO}$ mice represent a depression model with construct validity.

\section{Regulation of SERT ubiquitylation by MAGE-D1}

Some reports suggest that downregulation of the ubiquitylation-proteasome system is implicated in mood disorders, including depression. Transcriptome analysis in one such report revealed that the ubiquitin-mediated proteolysis pathway is implicated in depression-like behavior (Gormanns et al., 2011). In another report, gene expression analysis using postmortem samples showed that genes involved in the ubiquitin cycle are downregulated in bipolar disorders (Ryan et al., 2006). However, another report, a genome-wide association study, revealed that single nucleotide polymorphism of ubiquitin protein ligase E3C gene is associated with antidepressant response (Garriock et al., 2010). In addition, the ubiquitylation-proteasome system modulates the level of synaptic proteins and plays a critical role in synaptic trafficking (Wheeler et al., 2002; Yao et al., 2007). Another finding of relevance here is that ubiquitin-specific peptidase 46 (Usp46), which encodes a deubiquitinating enzyme, affects behavioral despair in forced swimming tests and tail suspension tests (Tomida et al., 2009).

It has been suggested that MAGE-D1 is involved in protein ubiquitylation in cooperation with praja-1 E3 ligases and recognizes the substrate as an adaptor molecule (Sasaki et al., 2002; Doyle et al., 2010). In the present study, MAGE-D1 colocalized with SERT in the some axons of the prefrontal cortex, and MAGE-D1 KO mice displayed an increase in SERT protein level without changes in mRNA expression via a decrease in its ubiquitylation in the prefrontal cortex. Transfection of MAGE-D1 in CHO-rSERT cells resulted in intracellular colocalization of MAGE-D1 with SERT, decreased serotonin reuptake activity, 
and a decrease in SERT protein expression associated with an increase in SERT ubiquitylation.

In vivo and in vitro immunoprecipitation studies have demonstrated that MAGE-D1 binds SERT via the NHD. SERT is regarded as a contributing factor for vulnerability to major depressive disorders and is an important target of many antidepressants (Hoefgen et al., 2005). It is also known that SERT levels are elevated in the brains of depressive patients (Reivich et al., 2004; Cannon et al., 2007). However, less is known about the molecule that is involved in the depressive state via its modulating of the metabolism of SERT. The present report is the first to reveal that SERT is ubiquitylated and that a deficiency in MAGE-D1 is implicated in depression-like behavior together with serotonergic hypofunction via an increase in SERT stability.

\section{Conclusion}

The other MAGE family protein, necdin, has been also reported to be an adaptor, and the gene encoding necdin has been described as the gene responsible for Prader-Willi syndrome (PWS) (Online Mendelian Inheritance in Men identification number 176270), a inheritable neurological disorder (Jay et al., 1997; MacDonald and Wevrick, 1997; Sutcliffe et al., 1997). It has been proposed that the adaptor function in ubiquitylation is a common feature of type II MAGE family proteins (Doyle et al., 2010). In addition, expression of necdin has been found to regulate epigenetically and that PWS is one imprinting disorder (Jay et al., 1997; MacDonald and Wevrick, 1997). Epigenetic control has been suggested to be involved in other mental disorders (Canli and Lesch, 2007; Tsankova et al., 2007). Whereas the nature of epigenetic control in expression of the Maged1 gene is not yet known, the MAGE family proteins may play a role in regulating mental activities though protein ubiquitylation under epigenetic control.

In summary, we identified one of the physiological roles of MAGE-D1 in depression-like behavior using MAGE-D1 KO mice. A deficiency in MAGE-D1 appears to be implicated in depression-like behavior together with hypofunction of the serotonergic system via a decrease in the ubiquitylation of SERT. The present results might contribute to the understanding of the neural and genetic mechanisms that underlie the mental disorders associated with MAGE-D1.

\section{References}

Ansorge MS, Zhou M, Lira A, Hen R, Gingrich JA (2004) Early-life blockade of the 5-HT transporter alters emotional behavior in adult mice. Science 306:879-881.

Barker PA, Salehi A (2002) The MAGE proteins: emerging roles in cell cycle progression, apoptosis, and neurogenetic disease. J Neurosci Res 67:705-712.

Bidziński A, Siemiatkowski M, Członkowska A, Tonderska A, Płaźnik A (1998) The effect of serotonin depletion on motor activity habituation, and $\left[{ }^{3} \mathrm{H}\right]$ muscimol binding in the rat hippocampus. Eur J Pharmacol 353:5-12.

Boyle MP, Brewer JA, Funatsu M, Wozniak DF, Tsien JZ, Izumi Y, Muglia LJ (2005) Acquired deficit of forebrain glucocorticoid receptor produces depression-like changes in adrenal axis regulation and behavior. Proc Natl Acad Sci USA 102:473-478.

Bull EJ, Hutson PH, Fone KC (2004) Decreased social behaviour following 3,4methylenedioxymethamphetamine (MDMA) is accompanied by changes in 5-HT2A receptor responsivity. Neuropharmacology 46:202-210.

Canli T, Lesch KP (2007) Long story short: the serotonin transporter in emotion regulation and social cognition. Nat Neurosci 10:1103-1109.

Cannon DM, Ichise M, Rollis D, Klaver JM, Gandhi SK, Charney DS, Manji HK, Drevets WC (2007) Elevated serotonin transporter binding in major depressive disorder assessed using positron emission tomography and $\left[{ }^{11} \mathrm{C}\right] \mathrm{DASB}$; comparison with bipolar disorder. Biol Psychiatry 62:870-877.

Crawley JN (1999) Behavioral phenotyping of transgenic and knockout mice: experimental design and evaluation of general health, sensory functions, motor abilities, and specific behavioral tests. Brain Res 835:18-26.

Cryan JF, Holmes A (2005) The ascent of mouse: advances in modelling human depression and anxiety. Nat Rev Drug Discov 4:775-790.

David DJ, Bourin M, Hascoet M, Colombel MC, Baker GB, Jolliet P (2001) Comparison of antidepressant activity in 4- and 40-week-old male mice in the forced swimming test: involvement of 5-HT1A and 5-HT1B receptors in old mice. Psychopharmacology (Berl) 153:443-449.

David DJ, Renard CE, Jolliet P, Hascoet M, Bourin M (2003) Antidepressantlike effects in various mice strains in the forced swimming test. Psychopharmacology (Berl) 166:373-382.

Dodart JC, Mathis C, Ungerer A (1997) Scopolamine-induced deficits in a two-trial object recognition task in mice. Neuroreport 8:1173-1178.

Doyle JM, Gao J, Wang J, Yang M, Potts PR (2010) MAGE-RING protein complexes comprise a family of E3 ubiquitin ligases. Mol Cell 39:963-974.

Duman RS, Heninger GR, Nestler EJ (1994) Molecular psychiatry. Adaptations of receptor-coupled signal transduction pathways underlying stressand drug-induced neural plasticity. J Nerv Ment Dis 182:692-700.

Ettenberg A, Le Moal M, Koob GF, Bloom FE (1983) Vasopressin potentiation in the performance of a learned appetitive task: reversal by a pressor antagonist analog of vasopressin. Pharmacol Biochem Behav 18:645-647.

Fernández Espejo E (1997) Structure of the mouse behaviour on the elevated plus-maze test of anxiety. Behav Brain Res 86:105-112.

File SE (1980) The use of social interaction as a method for detecting anxiolytic activity of chlordiazepoxide-like drugs. J Neurosci Methods 2:219-238.

Fukui M, Rodriguiz RM, Zhou J, Jiang SX, Phillips LE, Caron MG, Wetsel WC (2007) Vmat2 heterozygous mutant mice display a depressive-like phenotype. J Neurosci 27:10520-10529.

Fukuo Y, Kishi T, Kushima I, Yoshimura R, Okochi T, Kitajima T, Matsunaga S, Kawashima K, Umene-Nakano W, Naitoh H, Inada T, Nakamura J, Ozaki N, Iwata N (2011) Possible association between ubiquitinspecific peptidase 46 gene and major depressive disorders in the Japanese population. J Affect Disord 133:150-157.

Garriock HA, Kraft JB, Shyn SI, Peters EJ, Yokoyama JS, Jenkins GD, Reinalda MS, Slager SL, McGrath PJ, Hamilton SP (2010) A genomewide association study of citalopram response in major depressive disorder. Biol Psychiatry 67:133-138.

Gormanns P, Mueller NS, Ditzen C, Wolf S, Holsboer F, Turck CW (2011) Phenome-transcriptome correlation unravels anxiety and depression related pathways. J Psychiatr Res 45:973-979.

Hershko A, Ciechanover A (1982) Mechanisms of intracellular protein breakdown. Annu Rev Biochem 51:335-364.

Hoefgen B, Schulze TG, Ohlraun S, von Widdern O, Höfels S, Gross M, Heidmann V, Kovalenko S, Eckermann A, Kölsch H, Metten M, Zobel A, Becker T, Nöthen MM, Propping P, Heun R, Maier W, Rietschel M (2005) The power of sample size and homogenous sampling: association between the 5-HTTLPR serotonin transporter polymorphism and major depressive disorder. Biol Psychiatry 57:247-251.

Hofstetter JR, Hofstetter AR, Hughes AM, Mayeda AR (2005) Intermittent long-wavelength red light increases the period of daily locomotor activity in mice. J Circadian Rhythms 3:8.

Iida R, Yamada K, Mamiya T, Saito K, Seishima M, Nabeshima T (1999) Characterization of learning and memory deficits in C57BL/6 mice infected with LP-BM5, a murine model of AIDS. J Neuroimmunol 95:65-72.

Jay P, Rougeulle C, Massacrier A, Moncla A, Mattei MG, Malzac P, Roëckel N, Taviaux S, Lefranc JL, Cau P, Berta P, Lalande M, Muscatelli F (1997) The human necdin gene, NDN, is maternally imprinted and located in the Prader-Willi syndrome chromosomal region. Nat Genet 17:357-361.

Jordan BW, Dinev D, LeMellay V, Troppmair J, Gotz R, Wixler L, Sendtner M, Ludwig S, Rapp UR (2001) Neurotrophin receptor-interacting mage homologue is an inducible inhibitor of apoptosis protein-interacting protein that augments cell death. J Biol Chem 276:39985-39989.

Kasahara T, Kubota M, Miyauchi T, Noda Y, Mouri A, Nabeshima T, Kato T (2006) Mice with neuron-specific accumulation of mitochondrial DNA 
mutations show mood disorder-like phenotypes. Mol Psychiatry 11:577593, 523.

Kessler RC, Berglund P, Demler O, Jin R, Merikangas KR, Walters EE (2005) Lifetime prevalence and age-of-onset distributions of DSM-IV disorders in the National Comorbidity Survey Replication. Arch Gen Psychiatry 62:593-602.

Kuehner C (2003) Gender differences in unipolar depression: an update of epidemiological findings and possible explanations. Acta Psychiatr Scand 108:163-174.

Leach LS, Christensen H, Mackinnon AJ, Windsor TD, Butterworth P (2008) Gender differences in depression and anxiety across the adult lifespan: the role of psychosocial mediators. Soc Psychiatry Psychiatr Epidemiol 43:983-998.

Lister RG (1987) The use of a plus-maze to measure anxiety in the mouse. Psychopharmacology (Berl) 92:180-185.

Lu L, Mamiya T, Lu P, Niwa M, Mouri A, Zou LB, Nagai T, Hiramatsu M, Nabeshima T (2009) The long-lasting effects of cross-fostering on the emotional behavior in ICR mice. Behav Brain Res 198:172-178.

MacDonald HR, Wevrick R (1997) The necdin gene is deleted in PraderWilli syndrome and is imprinted in human and mouse. Hum Mol Genet 6:1873-1878.

Masuda Y, Sasaki A, Shibuya H, Ueno N, Ikeda K, Watanabe K (2001) Dlxin-1, a novel protein that binds Dlx5 and regulates its transcriptional function. J Biol Chem 276:5331-5338.

Matsuda T, Suzuki H, Oishi I, Kani S, Kuroda Y, Komori T, Sasaki A, Watanabe K, Minami Y (2003) The receptor tyrosine kinase Ror2 associates with the melanoma-associated antigen (MAGE) family protein Dlxin-1 and regulates its intracellular distribution. J Biol Chem 278:29057-29064.

Miyamoto Y, Yamada K, Noda Y, Mori H, Mishina M, Nabeshima T (2001) Hyperfunction of dopaminergic and serotonergic neuronal systems in mice lacking the NMDA receptor epsilon1 subunit. J Neurosci 21:750-757.

Miyamoto Y, Yamada K, Noda Y, Mori H, Mishina M, Nabeshima T (2002) Lower sensitivity to stress and altered monoaminergic neuronal function in mice lacking the NMDA receptor epsilon 4 subunit. J Neurosci 22:2335-2342.

Mouri A, Noda Y, Hara H, Mizoguchi H, Tabira T, Nabeshima T (2007a) Oral vaccination with a viral vector containing Abeta cDNA attenuates age-related Abeta accumulation and memory deficits without causing inflammation in a mouse Alzheimer model. FASEB J 21:2135-2148.

Mouri A, Noda Y, Noda A, Nakamura T, Tokura T, Yura Y, Nitta A, Furukawa H, Nabeshima T (2007b) Involvement of a dysfunctional dopamine-D1/Nmethyl-D-aspartate-NR1 and $\mathrm{Ca}^{2+} /$ calmodulin-dependent protein kinase II pathway in the impairment of latent learning in a model of schizophrenia induced by phencyclidine. Mol Pharmacol 71:1598-1609.

Mouri A, Noda Y, Shimizu S, Tsujimoto Y, Nabeshima T (2010) The role of cyclophilin D in learning and memory. Hippocampus 20:293-304.

Murai R, Noda Y, Matsui K, Kamei H, Mouri A, Matsuba K, Nitta A, Furukawa H, Nabeshima T (2007) Hypofunctional glutamatergic neurotransmission in the prefrontal cortex is involved in the emotional deficit induced by repeated treatment with phencyclidine in mice: implications for abnormalities of glutamate release and NMDA-CaMKII signaling. Behav Brain Res 180:152-160.

Nakamura K, Sugawara Y, Sawabe K, Ohashi A, Tsurui H, Xiu Y, Ohtsuji M, Lin QS, Nishimura H, Hasegawa H, Hirose S (2006) Late developmental stage-specific role of tryptophan hydroxylase 1 in brain serotonin levels. J Neurosci 26:530-534.

Overstreet DH (1993) The Flinders sensitive line rats: a genetic animal model of depression. Neurosci Biobehav Rev 17:51-68.

Owens MJ, NemeroffCB (1994) Role of serotonin in the pathophysiology of depression: focus on the serotonin transporter. Clin Chem 40:288-295.

Paylor R, Tracy R, Wehner J, Rudy JW (1994) DBA/2 and C57BL/6 mice differ in contextual fear but not auditory fear conditioning. Behav Neurosci 108:810-817.

Paxinos G, Franklin KB (2004) The mouse brain in stereotaxic coordinates, compact 2nd edition. San Diego: Elsevier.

Plotnikoff N, Reinke D, Fitzloff J (1962) Effects of stimulants on rotarod performance of mice. J Pharm Sci 51:1007-1008.

Põld M, Zhou J, Chen GL, Hall JM, Vescio RA, Berenson JR (1999) Identification of a new, unorthodox member of the MAGE gene family. Genomics 59:161-167.
Porsolt RD, Le Pichon M, Jalfre M (1977a) Depression: a new animal model sensitive to antidepressant treatments. Nature 266:730-732.

Porsolt RD, Bertin A, Jalfre M (1977b) Behavioral despair in mice: a primary screening test for antidepressants. Arch Int Pharmacodyn Ther 229:327-336.

Pothion S, Bizot JC, Trovero F, Belzung C (2004) Strain differences in sucrose preference and in the consequences of unpredictable chronic mild stress. Behav Brain Res 155:135-146.

Prut L, Belzung C (2003) The open field as a paradigm to measure the effects of drugs on anxiety-like behaviors: a review. Eur J Pharmacol 463:3-33.

Qiao H, Noda Y, Kamei H, Nagai T, Furukawa H, Miura H, Kayukawa Y, Ohta T, Nabeshima T (2001) Clozapine, but not haloperidol, reverses social behavior deficit in mice during withdrawal from chronic phencyclidine treatment. Neuroreport 12:11-15.

Reivich M, Amsterdam JD, Brunswick DJ, Shiue CY (2004) PET brain imaging with $\left[{ }^{11} \mathrm{C}\right](+) \mathrm{McN} 5652$ shows increased serotonin transporter availability in major depression. J Affect Disord 82:321-327.

Rice F, Harold G, Thapar A (2002) The genetic aetiology of childhood depression: a review. J Child Psychol Psychiatry 43:65-79.

Richelson E (2001) Pharmacology of antidepressants. Mayo Clin Proc 76:511-527.

Ryan MM, Lockstone HE, Huffaker SJ, Wayland MT, Webster MJ, Bahn S (2006) Gene expression analysis of bipolar disorder reveals downregulation of the ubiquitin cycle and alterations in synaptic genes. Mol Psychiatry 11:965-978.

Salehi AH, Roux PP, Kubu CJ, Zeindler C, Bhakar A, Tannis LL, Verdi JM, Barker PA (2000) NRAGE, a novel MAGE protein, interacts with the p75 neurotrophin receptor and facilitates nerve growth factor-dependent apoptosis. Neuron 27:279-288.

Sarter M, Bodewitz G, Stephens DN (1988) Attenuation of scopolamineinduced impairment of spontaneous alteration behaviour by antagonist but not inverse agonist and agonist beta-carbolines. Psychopharmacology (Berl) 94:491-495.

Sasaki A, Masuda Y, Iwai K, Ikeda K, Watanabe K (2002) A RING finger protein Prajal regulates Dlx5-dependent transcription through its ubiquitin ligase activity for the Dlx/Msx-interacting MAGE/Necdin family protein, Dlxin-1. J Biol Chem 277:22541-22546.

Sasaki A, Hinck L, Watanabe K (2005) RumMAGE-D the members: structure and function of a new adaptor family of MAGE-D proteins. J Recept Signal Transduct Res 25:181-198.

Sato T, Kitayama S, Mitsuhata C, Ikeda T, Morita K, Dohi T (2000) Selective inhibition of monoamine neurotransmitter transporters by synthetic local anesthetics. Naunyn Schmiedebergs Arch Pharmacol 361:214-220.

Sclafani A (2006) Enhanced sucrose and Polycose preference in sweet "sensitive" (C57BL/6J) and "subsensitive" (129P3/J) mice after experience with these saccharides. Physiol Behav 87:745-756.

Sogawa C, Sogawa N, Tagawa J, Fujino A, Ohyama K, Asanuma M, Funada M, Kitayama S (2007) 5-Methoxy- $N, N$-diisopropyltryptamine (Foxy), a selective and high affinity inhibitor of serotonin transporter. Toxicol Lett 170:75-82.

Stockmeier CA (2003) Involvement of serotonin in depression: evidence from postmortem and imaging studies of serotonin receptors and the serotonin transporter. J Psychiatr Res 37:357-373.

Sullivan PF, Neale MC, Kendler KS (2000) Genetic epidemiology of major depression: review and meta-analysis. Am J Psychiatry 157:1552-1562.

Sutcliffe JS, Han M, Christian SL, Ledbetter DH (1997) Neuronallyexpressed necdin gene: an imprinted candidate gene in Prader-Willi syndrome. Lancet 350:1520-1521.

Takezawa K, Okamoto I, Yonesaka K, Hatashita E, Yamada Y, Fukuoka M, Nakagawa K (2009) Sorafenib inhibits non-small cell lung cancer cell growth by targeting B-RAF in KRAS wild-type cells and C-RAF in KRAS mutant cells. Cancer Res 69:6515-6521.

Tavoulari S, Forrest LR, Rudnick G (2009) Fluoxetine (Prozac) binding to serotonin transporter is modulated by chloride and conformational changes. J Neurosci 29:9635-9643.

Thierry B, Steru L, Chermat R, Simon P (1984) Searching-waiting strategy: a candidate for an evolutionary model of depression? Behav Neural Biol 41:180-189.

Tomida S, Mamiya T, Sakamaki H, Miura M, Aosaki T, Masuda M, Niwa M, 
Kameyama T, Kobayashi J, Iwaki Y, Imai S, Ishikawa A, Abe K, Yoshimura T, Nabeshima T, Ebihara S (2009) Usp46 is a quantitative trait gene regulating mouse immobile behavior in the tail suspension and forced swimming tests. Nat Genet 41:688-695.

Tsankova N, Renthal W, Kumar A, Nestler EJ (2007) Epigenetic regulation in psychiatric disorders. Nat Rev Neurosci 8:355-367.

Walsh RN, Cummins RA (1976) The open-field test: a critical review. Psychol Bull 83:482-504.

Wheeler TC, Chin LS, Li Y, Roudabush FL, Li L (2002) Regulation of synaptophysin degradation by mammalian homologues of seven in absentia. J Biol Chem 277:10273-10282.

Williams ME, Strickland P, Watanabe K, Hinck L (2003) UNC5H1 induces apoptosis via its juxtamembrane region through an interaction with NRAGE. J Biol Chem 278:17483-17490.
Willner P (1991) Animal models as simulations of depression. Trends Pharmacol Sci 12:131-136.

Willner P, Towell A, Sampson D, Sophokleous S, Muscat R (1987) Reduction of sucrose preference by chronic unpredictable mild stress, and its restoration by a tricyclic antidepressant. Psychopharmacology (Berl) 93:358-364.

Yamada K, Iida R, Miyamoto Y, Saito K, Sekikawa K, Seishima M, Nabeshima T (2000) Neurobehavioral alterations in mice with a targeted deletion of the tumor necrosis factor-alpha gene: implications for emotional behavior. J Neuroimmunol 111:131-138.

Yao I, Takagi H, Ageta H, Kahyo T, Sato S, Hatanaka K, Fukuda Y, Chiba T, Morone N, Yuasa S, Inokuchi K, Ohtsuka T, Macgregor GR, Tanaka K, Setou M (2007) SCRAPPER-dependent ubiquitination of active zone protein RIM1 regulates synaptic vesicle release. Cell 130:943-957. 